\title{
Muscle oxygenation and ATP turnover when blood flow is impaired by vascular disease ${ }^{1}$
}

\author{
Graham J. Kemp ${ }^{\mathrm{a}, *}$, Neil Roberts ${ }^{\mathrm{b}}$, William E. Bimson ${ }^{\mathrm{b}}$, Ali Bakran ${ }^{\mathrm{c}}$ and Simon P. Frostick ${ }^{\mathrm{a}}$ \\ ${ }^{a}$ Department of Musculoskeletal Science, University of Liverpool, Liverpool L69 3GA, UK \\ ${ }^{\mathrm{b}}$ Magnetic Resonance and Image Analysis Research Centre, University of Liverpool, \\ Liverpool L69 3GA, UK \\ ${ }^{\mathrm{c}}$ Vascular Unit, Royal Liverpool University Hospital, Liverpool L69 3GA, UK
}

\begin{abstract}
In exercising muscle, creatine kinase ensures that mismatch between ATP supply and ATP use results in net phosphocreatine (PCr) splitting. This, inter alia, makes ${ }^{31} \mathrm{P}$ magnetic resonance spectroscopy a useful tool for studying muscle "energy metabolism' noninvasively in vivo. We combined this with near-infrared spectroscopy (NIRS) to study ATP synthesis and oxygenation in calf muscle of normal subjects and patients with peripheral vascular disease. Experimental and clinical details and basic data have been published elsewhere (G.J. Kemp et al., Journal of Vascular Surgery 34 (2001), 1103-10); we here propose an analysis of interactions between metabolic 'error signals' and cellular $\mathrm{PO}_{2}$ (estimated from NIRS changes, provisionally assumed to reflect deoxymyoglobin). Post-exercise PCr recovery is monoexponential, and the linear relationship between PCr resynthesis rate (= oxidative ATP synthesis) and the perturbation in $\mathrm{PCr}$ (conceptually the simplest error signal) is consistent with negative feedback. In patients the inferred 'mitochondrial capacity' (= oxidative ATP synthesis at 'zero' PCr) is decreased by $53 \pm 6 \%$, leading to reduced oxidative ATP contribution in exercise, because of increased deoxygenation. Increased PCr perturbation partially outweighs cellular hypoxia, but as low cellular $\mathrm{PO}_{2}$ is required for capillary-mitochondrion $\mathrm{O}_{2}$ diffusion, rate-signal relationships may overstate maximum oxidative ATP synthesis rate.
\end{abstract}

\section{Introduction}

What ${ }^{31} \mathrm{P}$ magnetic resonance spectroscopy (MRS) measures is limited in scope, sensitivity and quantifiability, but it does offer a valuable noninvasive window on ATP turnover in exercise. In this paper we review some of the principles of quantitative interpretation, and offer an analysis of relationships between tissue metabolism and vascular $\mathrm{O}_{2}$ transport as studied by combining ${ }^{31} \mathrm{P}$ MRS and near-infrared spectroscopy (NIRS) in normal subjects and in patients where these processes are impaired by peripheral vascular disease.

The key advantage of ${ }^{31} \mathrm{P}$ MRS is the ability to acquire multiple time-resolved measurements of exercise-recovery changes in phosphocreatine ( $\mathrm{PCr}$ ), inorganic phosphate $(\mathrm{Pi})$, cytosolic $\mathrm{pH}$, free ADP and the free energy of ATP hydrolysis $\left(\Delta G_{\mathrm{ATP}}\right)$, which can be used to study important aspects of ATP turnover (energy metabolism) and cellular acid-base physiology $\left(\mathrm{H}^{+}\right.$handling) $[1,2]$. One reason for this is the centrality to energy metabolism of the creatine kinase (CK) equilibrium, which has two main roles: first, to facilitate the diffusion of 'high energy phosphates' from sites of ATP production to sites of ATP use (a version of the 'phosphocreatine shuttle' concept $[3,4]$ which achieves 'spatial buffering'

\footnotetext{
${ }^{1}$ Some of this work was presented at the First International Conference on Biomedical Spectroscopy: From Molecules to Men, 7-10 July 2002, Cardiff, Wales.

*Corresponding author. Tel.: +44 151 7064124; Fax: +44 151 7065815; E-mail: gkemp@liv.ac.uk.
} 
of [ATP]); second, to ensure that that any mismatch between ATP supply and ATP use results in net PCr splitting (which achieves 'temporal buffering' of [ATP]). In the second role the CK system is an integrating comparator of rates of ATP synthesis and ATP use [5,6], and either the fall in [PCr] or the concomitant increases in [ADP], [Pi] and $\Delta G_{\text {ATP }}$ are potential closed-loop (negative-feedback) 'error signals' to regulate ATP production [2,5-9].

In appropriate experiments, dynamic ${ }^{31} \mathrm{P}$ MRS measurements can be used to measure rates of oxidative ATP synthesis $[8,10]$ and glycolytic ATP synthesis (i.e., that accompanied by lactic acid production) [11, 12]); contractile efficiency [13] (i.e., the efficiency with which ATP is used to generate force and/or do mechanical work); the cytosolic buffer capacity [12] and the rate of net acid $\left(\mathrm{H}^{+}\right)$efflux $[14,15]$. In general, some of these things must be assumed (or better, measured in a different experiment) in order to measure others $[1,2]$. Key points in these analyses are measurements of rates and rate constants, and quantitative models of physiology and metabolic control [1,2].

Here we focus on oxidative ATP synthesis in a moderately low power exercise (where the normal glycolytic contribution is small - 'pure' aerobic exercise) and in post-exercise recovery (which is always oxidative). A long-established approach to this takes ADP as an error signal stimulating oxidative (mitochondrial) ATP synthesis when this falls short of demand via an effect on the mitochondrial adenine nucleotide translocase $[7,9,16]$. As we shall see (Section 4.2) there is debate about several aspects of this. Nevertheless, there is common ground on the interpretation of ${ }^{31} \mathrm{P}$ MRS in 'aerobic' exercise [8,17] of the kind we are considering here, and it this analysis that we wish to extend.

An indispensable substrate for oxidative ATP synthesis is molecular $\mathrm{O}_{2}$, which is delivered from blood down a $\mathrm{PO}_{2}$ gradient [18] into the cell to the mitochondrion, where it is a substrate for cytochrome oxidase $[19,20]$. Inside the muscle cell its binding to myoglobin plays an important role in facilitating diffusion [21]. In steady state aerobic exercise the rate of $\mathrm{O}_{2}$ consumption $(=1 / 6$ of the oxidative ATP production rate [10]) must equal both the product of blood flow and the arteriovenous difference in $\mathrm{O}_{2}$ content (by the Fick principle), and the product of the capillary-mitochondrial $\mathrm{PO}_{2}$ gradient and diffusion coefficient (by definition [22]); and the near-mitochondrial $\mathrm{PO}_{2}$ must be high enough to drive cytochrome oxidase at the required rate, but low enough to permit $\mathrm{O}_{2}$ diffusion [22].

There are two noninvasive methods to study this: ${ }^{1} \mathrm{H}$ MRS detects deoxymyoglobin, and this can be used to calculate cellular $\mathrm{PO}_{2}$ [22]; alternatively, NIRS measures deoxygenation of haemoglobin in the capillary and/or myoglobin in the cell, in proportions which are debated [20,23] (and also, using specialised equipment and algorithms, the oxidation state of cytochrome oxidase [20]). Here we use NIRS in two ways. NIRS signal falls during exercise (denoting deoxygenation) because $\mathrm{O}_{2}$ demand exceeds vascular $\mathrm{O}_{2}$ supply, and we will describe how combined ${ }^{31} \mathrm{P}$ MRS/NIRS may be used to estimate the latter. Further, we will adapt an analysis of ${ }^{1} \mathrm{H}$ MRS deoxymyoglobin measurements [22] to estimate cellular $\mathrm{PO}_{2}$, and combine this with ${ }^{31} \mathrm{P}$ MRS data in order to relate the two kinds of driving force for mitochondrial ATP synthesis, viz. cellular $\mathrm{PO}_{2}$ and the perturbation of the CK equilibrium. The analysis will be rather schematic, somewhat dependent on assumed values of parameters which cannot yet be defined. However, it will illustrate some important principles, connecting the two 'worlds' of the ${ }^{31} \mathrm{P}$ MRS-based analysis of ATP turnover and the physiological/ ${ }^{1} \mathrm{H}$ MRS analysis of oxygen fluxes. We illustrate this with data from patients with peripheral vascular disease [24], in whom a defect of oxidative ATP synthesis results from chronic deficiency of vascular $\mathrm{O}_{2}$ supply. 


\section{Experimental subjects \& methods}

We studied patients with moderately severe peripheral vascular disease and age-matched controls. Experimental and clinical details and basic data have been published [24] and are summarised here.

\subsection{Subjects}

We report data from 8 moderate claudicants (aged 57-77 years) and 8 age-matched controls, all male. As our interest here is in the relationships between the abnormalities rather than their absolute sizes the patients were selected to minimise intragroup variability from 11 reported elsewhere [24] by excluding 3 with particularly low maximum voluntary contraction (MVC) force (almost certainly due to central fatigue phenomena irrelevant to the present analysis) and correspondingly low ATP turnover rates. Inclusion criteria were $\geqslant 6$ months intermittent calf claudication with proven femoro-popliteal or ilio-femoral occlusive or stenotic disease; maximum walking distance $<230 \mathrm{~m}\left(2 \mathrm{~km} / \mathrm{hr}, 10^{\circ}\right.$ gradient $)$; ankle-brachial pressure index $\leqslant 0.8$ (rest or exercise). Exclusion criteria were diabetes, anaemia or magnet contraindications. Each subject gave fully informed written consent, and the work was conducted with the approval of the Liverpool Research Ethics Committee, in accordance with the Declaration of Helsinki of the World Medical Association. Smoking was forbidden for 2 hours before each study. Each subject was studied on three occasions within 1-12 weeks (median 5 weeks), and the results presented are the mean of the three studies, which did not differ significantly.

\subsection{Experimental methods}

${ }^{31} \mathrm{P}$ MRS was performed as described elsewhere [24]. In a Signa Advantage 1.5 tesla whole body MR system (General Electric, Milwaukee, WI), subjects lay supine on a rig permitting isometric plantarflexion against an upright pedal, with LED force feedback. MVC was measured before each study. An axial $\mathrm{T}_{2}$-weighted spin echo MR image was obtained for measuring cross-sectional area. ${ }^{31} \mathrm{P}$ MRS data were acquired with a $10 \times 6 \mathrm{~cm}$ elliptical RF surface coil over the right lateral belly of gastrocnemius. NIRS data was acquired simultaneously from the same site using a Runman CES-2000 instrument (NIM Inc, Philadelphia, PA) with lightguides passing through the RF coil. After $\mathrm{B}_{0}$ field homogeneity was optimised by manually shimming on a water signal, ${ }^{31} \mathrm{P}$ spectra were obtained with $2 \mathrm{~s}$ repetition time at rest (128 scans), and then throughout an exercise/recovery protocol (8-scan spectra). Exercise was audiblycued voluntary $0.5 \mathrm{~Hz}$ isometric plantarflexion with $50: 50$ duty cycle. The protocol comprised 3 spectra at rest, 12 spectra during exercise at $50 \%$ MVC (3.2 $\mathrm{min})$ followed by 20 recovery spectra $(5.3 \mathrm{~min})$; then 8 spectra during exercise at $75 \%$ MVC $(2.1 \mathrm{~min})$ followed by 20 recovery spectra $(5.3 \mathrm{~min})$; the second (75\% MVC) exercise/recovery was then repeated. If exercise ended early because of fatigue or pain, recovery collection started early, but the next exercise started at the normal time. Force and NIRS data were captured via a PowerLab ADI on a PC running Chart software (ADInstruments Ltd, Hastings, UK). Data from the two 75\% MVC exercise periods did not differ significantly, and were combined.

The NIRS signal (digitised manually in Chart) represents the difference in absorption at two wavelengths, proportional to deoxygenated haemoglobin + myoglobin content $[20,23,25]$ (we discuss the possible contribution of each later). Changes were normalised for instrument gain using the difference between the calibration signals at the two wavelengths, as scaling to maximum signal change in exhaustive ischaemic exercise [25] was not tolerated by all subjects. For inferences about cellular $\mathrm{PO}_{2}$ (see Section 2.6) we take the maximum deoxygenation in subjects who were able to tolerate this as representative of the whole group. The maximum cross-sectional area of the posterior calf (i.e., soleus + gastrocnemius) 
was measured by point-counting [26] using ANALYZE software (Mayo Foundation, Minnesota, USA), and found not to differ between the two groups. ${ }^{31} \mathrm{P}$ MRS data were analysed using Magnetic Resonance User Interface software (MRUI 97.1), which implements the AMARES time-domain fitting algorithm. Resting spectra were fitted with 10 Lorentzian peaks: Pi, phosphodiester, phosphocreatine (PCr), 2 peaks (amplitude ratio $1: 1$ ) each for $\gamma$-ATP and $\alpha$-ATP and 3 (amplitude ratio $1: 2: 1$ ) for $\beta$-ATP; exercise spectra were fitted with three: Pi, PCr and ATP (no significant changes in ATP were observed).

Intracellular $\mathrm{pH}$ was calculated from the chemical shift of $\mathrm{Pi}$ relative to $\mathrm{PCr}$ ( $\sigma$ parts per million) [27], as $\mathrm{pH}=6.8+\log _{10}\{(\sigma-3.27) /(5.69-\sigma)\}$. To avoid problems of absolute quantification, changes in $\mathrm{PCr}$ and derived quantities were expressed where possible relative to resting $\mathrm{PCr}$ concentration. For some of the analysis absolute quantification is necessary, and for this (see Appendix) we take resting [PCr] as $35 \mathrm{mmol}\left(1\right.$ cell water) ${ }^{-1}$ (units which we will refer to simply as mmol $1^{-1}$ ). Assuming creatine kinase remains at equilibrium, and given that total creatine $(\mathrm{TCr}=\mathrm{PCr}+$ creatine) remains constant during exercise and recovery, ADP concentration is calculated as $[\mathrm{ADP}]=[\mathrm{ATP}]\{([\mathrm{TCr}] /[\mathrm{PCr}])-$ $1\} /\left(K_{\mathrm{CK}}^{\mathrm{app}}\left[\mathrm{H}^{+}\right]\right)$, where [ADP], [ATP] and [PCr] are understood as [ $\left.\sum \mathrm{ADP}\right]$, [ $\left.\sum \mathrm{ATP}\right]$ and [ $\left.\sum \mathrm{PCr}\right]$, i.e., the sum of all the relevant ionic species (we can neglect species of free creatine), and $K_{\mathrm{CK}}^{\mathrm{app}}$ is an apparent equilibrium constant [12]. We make the conventional assumptions of $8.2 \mathrm{mmol}^{-1}$ ATP concentration and $42 \mathrm{mmol}^{-1}$ total creatine, based on biopsy data from quadriceps [27,28], and as $\mathrm{pH}$ changes are small we can take $K_{\mathrm{CK}}^{\mathrm{app}} \approx 1.66 \times 10^{9} 1 \mathrm{~mol}^{-1}$ [10]. The free energy of ATP hydrolysis is calculated as $\Delta G_{\mathrm{ATP}}=\Delta G_{\mathrm{ATP}}^{0}+R T \ln \{[\mathrm{ADP}][\mathrm{Pi}] /[\mathrm{ATP}])$, where the gas constant $R=8.3145 \mathrm{~K}^{-1} \mathrm{~mol}^{-1}$, the absolute temperature $T=310 \mathrm{~K}$ and $\Delta G_{\mathrm{ATP}}^{0}=-32 \mathrm{~kJ} \mathrm{~mol}^{-1}$ [10]. Pi is calculated from Pi/ATP using saturation factors derived from fully relaxed spectra ( $15 \mathrm{~s}$ repetition time).

\subsection{Analysis of fluxes in exercise}

How we can use ${ }^{31} \mathrm{P}$ MRS and NIRS as a window on muscle metabolism and vascular physiology is shown diagrammatically in Fig. 1 and described in the legend. In exercise, ATP hydrolysis by the myosin ATPase is used for mechanical work, while creatine kinase allows near-simultaneous rephosphorylation of ADP by $\mathrm{PCr}$ [2]. The sum of these is $\mathrm{PCr}$ 'splitting', the Lohmann reaction ( $\mathrm{PCr} \Rightarrow \mathrm{Pi}+$ creatine) supplying 1 'ATP unit' of energy per PCr, which buffers ATP by balancing any mismatch between ATP use and 'metabolic' ATP supply [2,6,29]. We take total ATP turnover rate as the sum of a component $\left(F_{\mathrm{F}}\right)$ driving the actomyosin ATPase and generating force, and a 'basal' component $\left(F_{\mathrm{B}}\right)$ driving mainly the sarcoplasmic reticulum $\mathrm{Ca}^{2+}$-ATPase [30]. Equating this to ATP production by oxidative metabolism $(Q)$, glycolysis to lactate $(L)$ and $\mathrm{PCr}$ splitting $(D=-\mathrm{d}[\mathrm{PCr}] / \mathrm{d} t)$, we have $F_{\mathrm{F}}+F_{\mathrm{B}}=Q+$ $D+L$. In resting muscle $F_{\mathrm{F}}=L=0$, and $F_{\mathrm{B}}$ is supplied by basal oxidative ATP synthesis $\left(Q_{\mathrm{B}}\right)$; from measurements of muscle $\mathrm{O}_{2}$ uptake [31], $Q_{\mathrm{B}} \approx 1-2 \mathrm{mmoll}^{-1} \mathrm{~min}^{-1}$, much less here than the forcegenerating component $F_{\mathrm{F}}$. As initial $L=Q-Q_{\mathrm{B}}=0$, we can take the initial rate of PCr depletion as a measure of ATP turnover $F_{\mathrm{F}}[13,32,33]$. This divided by force output per unit cross-sectional area is the contractile cost [32]), whose reciprocal is the contractile efficiency; this is a function of fibre type [34] and exercise mechanism [35,36].

Rates of PCr depletion were calculated from a least-squares monoexponential fit [8] $-\Delta[\mathrm{PCr}]=$ $-\Delta[\mathrm{PCr}]_{S S}[1-\exp (-k t)]$ where $k$ is a rate constant $\left(=0.693 / t_{1 / 2}\right), t$ is the time after end of exercise, and $-\Delta[\mathrm{PCr}]_{S S}$ is the implied steady-state amount by which [PCr] falls below its resting value. The instantaneous rate of $\mathrm{PCr}$ depletion during exercise is then $D=-k \Delta[\mathrm{PCr}]_{\mathrm{SS}} \exp (-k t)$ from which the initial-exercise rate is $D_{0}=-k \Delta[\mathrm{PCr}]_{\mathrm{SS}}$, an estimate of $F_{\mathrm{F}}$. When fitted without constraints, the rates at $75 \% \mathrm{MVC}$ and 50\% MVC were linear with force, as expected [13,37,38], so to improve precision we 


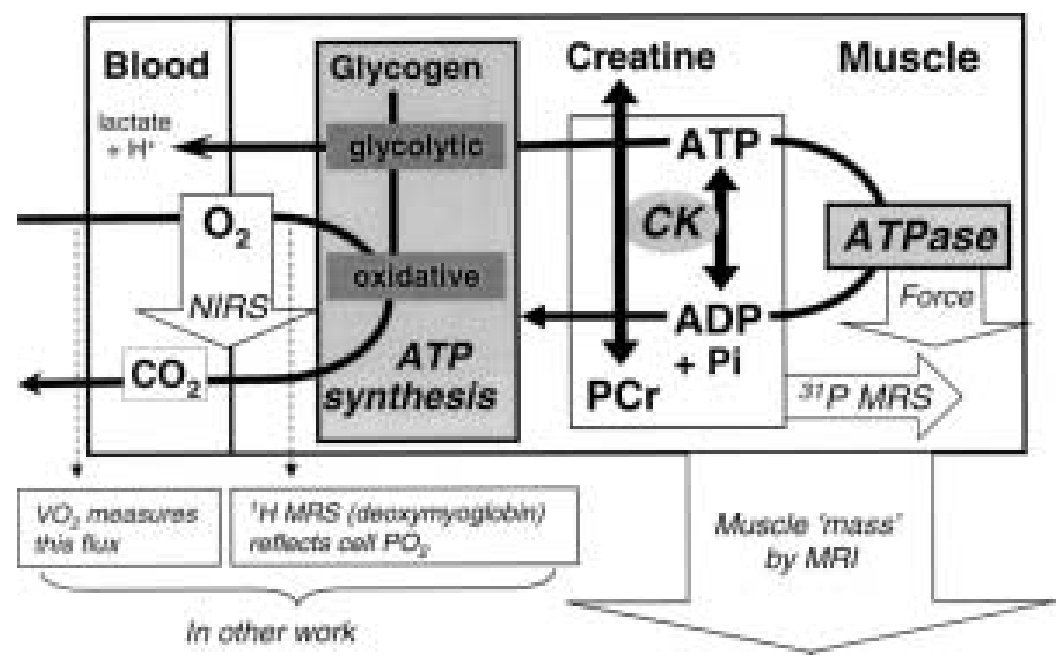

Fig. 1. How ${ }^{31} \mathrm{P}$ MRS and NIRS 'see' muscle metabolism (see Section 2.4). ${ }^{31} \mathrm{P}$ MRS can measure PCr, Pi and ATP directly, $\mathrm{ADP}$ and $\mathrm{pH}$ indirectly. ATP is generated from nonoxidative glycolysis to lactate and (much more efficiently) by full oxidation, and used largely by the myosin ATPase to generate force (neglecting here the sarcoplasmic reticulum $\mathrm{Ca}^{2+}$-ATPase [30]). If ATP use during exercise exceeds production, creatine kinase (CK) uses phosphocreatine (PCr) to regenerate ATP from ADP: this is equivalent to $\mathrm{PCr}$ 'splitting' to creatine $+\mathrm{Pi}$, while ATP remains stable (at millimolar concentrations) and ADP increases (at micromolar concentrations) [29]. Thus PCr change reflects mismatch between ATP synthesis and use [5,6]. It is postulated that by negative feedback [6] the associated increases in Pi and ADP help to stimulate glycolytic [12] and oxidative [7] ATP synthesis, and by studying flux-signal transfer functions ${ }^{31} \mathrm{P}$ MRS can study this directly, e.g. [7,9,10,48,49]; however, direct (feedforward) activation is probably dominant in the control of glycolysis $[11,12,16]$ and may also be important in oxidative ATP synthesis [62]; these mechanisms can only be studied indirectly by ${ }^{31} \mathrm{P}$ MRS. Protons produced with lactate are partly 'consumed' by PCr splitting (not shown) [12,122], or leave the cell; those that remain acidify the cell, to a rather small degree in the present case. In recovery from exercise, PCr is restored by oxidative ATP production [10]. We use PCr measurements to calculate the use and oxidative supply of ATP. Muscle oxygenation changes are the result of vascular $\mathrm{O}_{2}$ supply (not measured) and mitochondrial $\mathrm{O}_{2}$ consumption (obtained from ${ }^{31} \mathrm{P}$ MRS); NIRS signal reflects deoxyhaemoglobin in muscle capillaries and deoxymyoglobin in the muscle cell in currently uncertain proportions [20,23,25]. For completeness the figure also illustrates the use of MRI for measurements of muscle cross-sectional area, invasive arteriovenous difference (AVD) measurements for measuring $\mathrm{O}_{2}$ uptake directly [123], and noninvasive ${ }^{1} \mathrm{H}$ MRS measurements of deoxymyoglobin [22]. Lactate and proton efflux can also be measured directly by invasive AVD methods [124] (not shown).

refitted the data with this as a constraint [24]. To allow for the complicating effects of non-negligible glycolytic ATP synthesis in the patients (a departure from the 'pure aerobic' exercise model [8]), we did not constrain the rate constants of $\mathrm{PCr}$ depletion during exercise and post-exercise $\mathrm{PCr}$ recovery to be the same.

Although in exercise and early recovery the restoration of ion gradients [39] must increase the nonforce-generating component $F_{\mathrm{B}}$ above $Q_{\mathrm{B}}$, we make the conventional assumption (experimentally confirmed at least for steady-state exercise [10]) that this can be neglected. The 'ATP balance' equation thus simplifies to $F_{\mathrm{F}}=Q+D+L$. We follow [16] in 'predicting' oxidative ATP synthesis in exercise (trivially modified by assuming a constant relationship to [PCr] rather than [ADP]) then estimating glycolytic ATP synthesis rate as $L=F_{\mathrm{F}}-Q-D$.

\subsection{Analysis of fluxes in recovery from exercise}

At the end of exercise, lactate production stops immediately [40], or nearly so [39], so recovery is overwhelmingly oxidative [41]. Mechanical work has ceased $\left(F_{\mathrm{F}}=0\right)$, but suprabasal oxidative ATP synthesis continues, balanced by rephosphorylation of creatine by ATP. The sum of these is a reverse 
Lohmann reaction, the net resynthesis of $\mathrm{PCr}(\mathrm{Pi}+$ creatine $\Rightarrow \mathrm{PCr})$, using 1 ATP per PCr. Eventually $Q$ returns to zero (i.e., zero above basal) as $\mathrm{PCr}$ returns to resting levels. Thus the rate of $\mathrm{PCr}$ resynthesis in recovery (which we call $V=\mathrm{d}[\mathrm{PCr}] / \mathrm{d} t$ ) is a measure of $Q$ less the basal component [10]: $Q=V+Q_{\mathrm{B}}$.

To obtain the halftime of $\mathrm{PCr}$ recovery we fit $\mathrm{PCr}$ changes during recovery to a monexponential equation [8] $-\Delta[\mathrm{PCr}]=-\Delta[\mathrm{PCr}]_{0} \exp (-k t)$ where $k$ is a rate constant $\left(=0.693 / t_{1 / 2}\right), t$ is now the time after end of exercise, and $-\Delta[\mathrm{PCr}]_{0}$ is the initial-recovery (i.e., end-exercise) amount by which [PCr] has fallen below its resting value. The instantaneous rate of $\mathrm{PCr}$ resynthesis during recovery is then $V=-k \Delta[\mathrm{PCr}]_{0} \exp (-k t)$ from which the initial-recovery rate is $V_{0}=-k \Delta[\mathrm{PCr}]_{0}$ which can be taken as a measure of end-exercise $Q$, or more exactly $Q-Q_{\mathrm{B}}$ (see above).

\subsection{Analytical models of the regulation of oxidative ATP synthesis}

We used values of $V_{0}$ estimated from the fit throughout recovery (see previous section) to plot the relationships between $Q$ and [ADP], $-\Delta[\mathrm{PCr}]$ and $\Delta G_{\mathrm{ATP}}$, basing these on three candidate models for the control of mitochondrial ATP synthesis. The 'linear model' is based on the fact that for monoexponential $\mathrm{PCr}$ recovery, $V$ is linear with $-\Delta[\mathrm{PCr}$ ], with slope equal to the rate constant $k$ [8]. If this relationship holds, then extrapolating linearly to complete $\mathrm{PCr}$ depletion yields an estimate of $Q_{\mathrm{MAX}}$, the maximal rate of oxidative ATP synthesis: $Q_{\mathrm{MAX}} \approx k[\mathrm{PCr}]_{\mathrm{BASAL}},[6,42]$. We use this model in reverse to calculate the (hypothetical) rates of oxidative ATP synthesis during exercise from the observed [PCr] during exercise: $Q=-k \Delta[\mathrm{PCr}]$. This is the source of the values of $Q$ used in the analysis of exercise (Section 2.3). In the ADP-control model we follow $[9,43]$ in fitting a sigmoid curve $V+Q_{\mathrm{B}}=Q_{\mathrm{MAX}} /\left\{1+\left(K_{\mathrm{m}} /[\mathrm{ADP}]\right)^{n}\right\}$, where $K_{\mathrm{m}}$ is the [ADP] for half-maximal rate and $n$ is the Hill coefficient: we use a free fit on mean data from both exercise intensities to give overall estimates of $K_{\mathrm{m}}, Q_{\mathrm{B}}$ and $n$; we then use these with individual values of $V_{0}$ and the end-exercise [ADP], to obtain individual values of $Q_{\mathrm{MAX}}=\left(V_{0}+\right.$ $\left.Q_{\mathrm{B}}\right)\left\{1+\left(K_{\mathrm{m}} /[\mathrm{ADP}]_{0}\right)^{n}\right\}$.

In the non-equilibrium thermodynamic model, based on the relationship between flux and $\Delta G_{\text {ATP }}$ there are two levels of approximation. A simple analysis [8] of aerobic exercise/recovery is based on the nearlinear relationship between $Q$ and $\Delta G_{\mathrm{ATP}}$, whose slope $\mathrm{d} Q / \mathrm{d} \Delta G_{\mathrm{ATP}}$ (the mitochondrial conductance, in a convenient electrical analogy [8]), is a measure of mitochondrial capacity, and whose intercept $\Delta G_{\mathrm{MITO}}$, the mitochondrial potential, is the State 4 'static head', i.e., the value of $\Delta G_{\mathrm{ATP}}$ at which $Q$ is zero (not $V$, which is zero at rest). More exactly, though, this relationship is sigmoid [44,45]. We use this in the form

$$
V+Q_{\mathrm{B}}=\frac{Q_{\mathrm{MAX}}\left\{\exp \left[a\left(\Delta G_{\mathrm{ATP}}-\Delta G_{\mathrm{MITO}}\right) / R T\right]-1\right\}}{\exp \left[a\left(\Delta G_{\mathrm{ATP}}-\Delta G_{\mathrm{MITO}}\right) / R T\right]+1 / b},
$$

where $a$ for a unimolecular substrate-to-product reaction would be unity [46], and $b$ is the (small) ratio of the maximum reverse flux to the maximum forward flux. We take $b=0.08$ [44] and obtain $Q_{\mathrm{B}}$ and $\Delta G_{\text {MITO }}$ from a free fit on mean data from both exercise intensities; we then use these with individual values of $V_{0}$ and end-exercise $\Delta G_{\mathrm{ATP}}$ to obtain individual $Q_{\mathrm{MAX}}$. (If desired a linear approximation can be constructed by noting that the midpoint of this expression is at $\Delta G_{\mathrm{ATP}}-\Delta G_{\mathrm{MITO}}=-R T \ln (b) / a$, where the slope is $[a /(4 R T)](1+b)$ (modified from [46]).

\subsection{Analysis of NIRS data}

NIRS falls during exercise because $\mathrm{O}_{2}$ demand exceeds vascular $\mathrm{O}_{2}$ supply, vice versa in recovery. NIRS recovery is assessed using the time to half recovery, which for purpose of comparison with PCr 
kinetics is converted into an effective quasi-exponential rate constant. We use a running 3-point linear regression to measure absolute rates of change of NIRS during exercise and recovery. This is related to the difference between $\mathrm{O}_{2}$ use and $\mathrm{O}_{2}$ supply, and we have information on the former from analysis of PCr kinetics (Sections 2.3 and 2.4). Thus we calculate the rate of $\mathrm{O}_{2}$ supply (equal to the product of blood flow and the AV difference in $\mathrm{O}_{2}$ content) as $S=Q / 6+\Psi(\mathrm{d} N I R S / \mathrm{d} t)$, although it is convenient to express this as a notional maximum oxidative ATP synthesis, $6 S=Q+6 \Psi(\mathrm{d} N I R S / \mathrm{d} t)$, where the factor 6 is the $\mathrm{P}: \mathrm{O}$ ratio [10]. In these expressions $\Psi$ is a calibration factor to which no precise value can be given at present; here we use the requirement for $S$ to be positive to fix a maximum value, corresponding to the largest abnormality in patients.

We also use NIRS data, and maximum NIRS changes in ischaemic exercise (not tolerated in all subjects), follow [23] in taking NIRS as a measure of deoxymyoglobin, then use this to estimate cellular $\mathrm{PO}_{2}$ [22]. The upper line in Fig. 5C represents the $\mathrm{PO}_{2}$-dependence of maximum oxidative ATP synthesis rate (cf. similar plots using data from exercise under hypoxia, normoxia and hyperoxia [22,47]), obtained here using a hyperbolic fit to 'maximum rates' at 50\% \& 75\% MVC obtained from Fig. 4A by linear extrapolation to complete PCr depletion (see Section 2.5). We further assume (for the sake of argument) that linearity also holds at fixed $\mathrm{PO}_{2}$ in order to construct the two lower curves, which represent the hypothetical $\mathrm{PO}_{2}$-dependence of oxidative ATP synthesis rate with $\mathrm{PCr}$ 'clamped' at the end-exercise value at each of the two exercise intensities. Thus the representative point moves along these in response to changed $\mathrm{PO}_{2}$, and vertically in response to changed in [PCr]. The diagonal 'diffusion' line [22] is arranged to fit both exercise intensities in controls, and to be of the same slope (i.e., a normal diffusion capacity) in patients. The steady-state point is at the intersection of the two kinds of line, and that for steady-state exercise is marked with the labelled square.

\subsection{Statistics \& data presentation}

Results are presented as mean \pm SEM. Differences between values at 50\% and $75 \%$ MVC exercise are assessed using Student's paired $t$-test. Differences between mean values in patients and controls are assessed using Student's unpaired $t$-test. Where a significant difference in a mean value is demonstrated, the patient/control ratio (mean $\pm \mathrm{SEM}$, using standard error-propagation analysis) gives a useful guide to the size of the defect.

\section{Results}

\subsection{PCr changes and rates of ATP synthesis (Fig. 2)}

The overall time course of PCr changes in 50\% MVC exercise and recovery is shown in Fig. 2A, together with some legends and labels which show how the ATP synthesis rates shown in Fig. 2B are obtained. PCr falls during exercise and rises during recovery, as expected, in an exponential way (Fig. 2A). The total (end-exercise) $\mathrm{PCr}$ change is just significantly greater in patients than controls $(31 \pm 3 \%$ vs $21 \pm 3 \%$ of basal, $P=0.047$ ), while the inferred steady-state change in $\operatorname{PCr}\left(=D_{0} /\right.$ (rate constant of $\mathrm{PCr}$ depletion)) was substantially so $(60 \pm 8 \%$ vs $32 \pm 8 \%$ of basal, $P=0.03)$. The initial rate of $\mathrm{PCr}$ depletion $\left(\approx\right.$ ATP turnover rate [13]) was $24 \pm 3 \mathrm{mmoll}^{-1} \mathrm{~min}^{-1}$ in patients, not significantly different from $24 \pm 3 \mathrm{mmoll}^{-1} \mathrm{~min}^{-1}$ in controls. As the muscle areas also did not differ, we can infer a normal contractile efficiency. The PCr recovery rate constant did not differ significantly between $50 \%$ and $75 \%$ MVC, and its mean value was $1.0 \pm 0.1 \mathrm{~min}^{-1}$ in patients, significantly smaller than $2.2 \pm 0.2 \mathrm{~min}^{-1}$ 


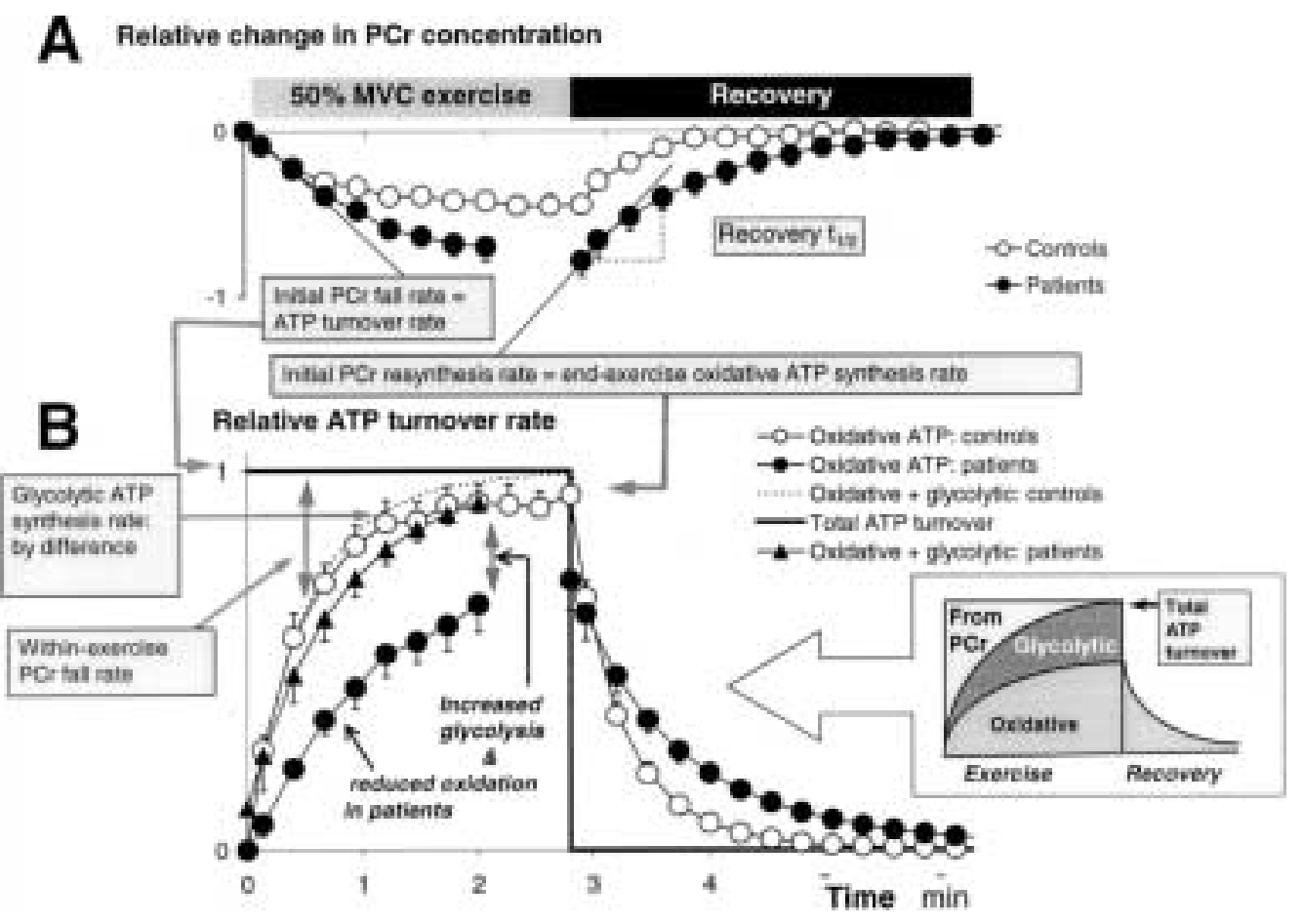

Fig. 2. MRS changes during exercise and recovery, and principles of analysis. This figure combines observed changes in $\mathrm{PCr}$ (panel A) and inferred rates of ATP turnover (panel B) during exercise at 50\% MVC and subsequent recovery, together with labels describing the principles of analysis. Results are mean \pm SEM for patients (solid circles) and control subjects (open circles), shown as composite presentations of mean values from studies in which, especially for patients, exercise duration was often reduced; this is indicated by breaks in the graphs. (A) shows PCr kinetics, expressed relative to baseline. In general ATP turnover $=$ glycolytic ATP synthesis rate + oxidative ATP synthesis rate $+\mathrm{PCr}$ splitting rate. At the very start of exercise the first two are negligible, so the initial rate of PCr splitting measures ATP turnover [13,33]. This is proportional to force/area; the inverse of the slope (= contractile cost) $[13,33]$ is the contractile efficiency. Subsequently PCr splitting slows as oxidative and/or glycolytic ATP synthesis increase, and a steady state is reached. In this largely aerobic constant-power exercise, $\mathrm{PCr}$ kinetics are exponential [8] (but not necessarily otherwise [12]). The initial post-exercise PCr resynthesis rate is a measure of the end-exercise oxidative ATP synthesis rate [10] (neglecting non-contractile ATP use). In the absence of sizeable pH change, $\mathrm{PCr}$ recovery kinetics are exponential, and we measure the halftime to obtain the rate constant. Changes in free [ADP] and $\Delta G_{\text {ATP }}$ (not shown) are roughly the inverse of changes in PCr, showing a rise in exercise, followed by exponential recovery [8]. (B) shows ATP turnover rates, scaled to initial ATP turnover (= initial-exercise PCr depletion rate), and expressed additively, so that ATP turnover rate (solid line) is 1 during exercise (assuming constant contractile efficiency), and zero during recovery. Other rates are as labelled ('glycolytic + oxidative' ATP synthesis is similar in the two groups, although the oxidative contribution is decreased and the glycolytic increased in patients). Initial post-exercise PCr resynthesis rate $=$ end-exercise oxidative ATP synthesis rate, and this declines with the same halftime as PCr concentration in Panel A. Making a small correction for end-exercise rate of PCr splitting, total ATP turnover rate (estimated as initial-exercise PCr depletion rate) minus initial post-exercise PCr resynthesis rate (= end-exercise oxidative ATP synthesis rate) gives end-exercise glycolytic ATP synthesis rate. We extend this forward in exercise by estimating oxidative synthesis rate using a model of mitochondrial control which will be described in Fig. 4A. (A different approach estimates lactate accumulation from $\mathrm{pH}$ and $\mathrm{PCr}$ changes [12], either ignoring acid efflux [61] or attempting to correct for it [109,111]; here, where $\mathrm{pH}$ changes are small, all approaches agree in finding relatively negligible glycolytic ATP synthesis in controls [24].)

in controls $(P<0.0001)$. The absolute initial rate of $\mathrm{PCr}$ resynthesis after $50 \%$ MVC exercise was $18 \pm 3 \mathrm{mmol}^{-1} \mathrm{~min}^{-1}$ in patients, not significantly smaller than $24 \pm 3 \mathrm{mmol}^{-1} \mathrm{~min}^{-1}$ in controls; however a significant difference was observed in the rates after $75 \%$ MVC exercise $\left(21 \pm 2 \mathrm{mmoll}^{-1} \mathrm{~min}^{-1}\right.$ in patients vs $33 \pm 4 \mathrm{mmoll}^{-1} \mathrm{~min}^{-1}$ in controls, $P=0.02$ ). $\mathrm{pH}$ changes were small (not shown) and 
not significantly different in patients. The kinetics of [ADP] and $\Delta G_{\text {ATP }}$ (not shown) broadly mirrored that of $\mathrm{PCr}$.

Figure 2 shows how the initial rate of $\mathrm{PCr}$ depletion is used to establish the rate of ATP turnover; assuming constant contractile efficiency, this holds through exercise (thick horizontal line, whose $y$ value in this scaled plot is unity) before fall abruptly to zero at the end of exercise; in recovery, $\mathrm{PCr}$ resynthesis exactly matches oxidative ATP synthesis and so net ATP used by the myosin ATPase is zero. It can be seen that for controls this exercise is almost entirely oxidative, i.e., glycolytic ATP synthesis is negligible. Expressed as fraction of total ATP turnover, the initial rate of $\mathrm{PCr}$ resynthesis was significantly lower in patients after exercise at both $50 \%$ MVC $(0.71 \pm 0.08$ vs $0.94 \pm 0.05, P=0.03)$ and $75 \%$ MVC $(0.59 \pm 0.05$ vs $0.99 \pm 0.03, P=0.001)$. Thus for patients there is a shortfall in ATP synthesis; this follows directly from the reduced initial rate of post-exercise PCr recovery - which gives the end-exercise rate - and is inferred in the rest of exercise by using the relationship between oxidative ATP synthesis and $\mathrm{PCr}$ change which will be presented in Fig. 4A. Some of this shortfall is made up by increased $\mathrm{PCr}$ depletion, and some by increased glycolytic ATP synthesis (see Section 3.4).

\subsection{NIRS changes and rates of oxygen supply and use (Fig. 3)}

Figure 3A shows deoxygenation during exercise and reoxygenation following. In individual subjects, a variety of small-scale lag and overshoot phenomena can be seen, but these are averaged into something approaching exponential kinetics. The size of the changes is larger in patients than controls, and the recovery visibly much slower. Recovery is conveniently expressed as a halftime or the corresponding 'rate constant', and as this did not differ significantly between $50 \%$ and $75 \% \mathrm{MVC}$ we combine these, giving $0.32 \pm 0.04 \mathrm{~min}^{-1}$ in patients, significantly less than $1.0 \pm 0.1 \mathrm{~min}^{-1}$ in controls $(P=0.0003)$. We have made elsewhere [24] the admittedly simplistic point that the larger fractional abnormality in 'NIRS rate constant' (which in patients is only $0.32 \pm 0.05$ of the control value) than that in $\mathrm{PCr}$ rate constant $(0.46 \pm 0.05$ of control $)$ is consistent with the cause-effect relationship of $\mathrm{O}_{2}$ supply defect and mitochondrial dysfunction; simplistic because NIRS recovery is a function of $\mathrm{O}_{2}$ use as well as $\mathrm{O}_{2}$ supply and because $\mathrm{O}_{2}$ supply is a function of $\mathrm{AV}\left[\mathrm{O}_{2}\right]$ difference as well as flow.

Figure 3B shows the rates of change of NIRS signal. Differences in these absolute rates are too small to be detectable in recovery; however the increased $(P=0.03)$ rate of deoxygenation during exercise in patients - despite reduced $\mathrm{O}_{2}$ consumption - is well shown. Figure $3 \mathrm{C}$ takes this analysis further and shows, in admittedly schematic form, the abnormality in net $\mathrm{O}_{2}$ supply. This is proportionally larger than the effect in oxygen usage, otherwise NIRS would not show faster deoxygenation and slower reoxygenation in patients.

\subsection{PCr resynthesis and the control of mitochondrial ATP synthesis (Fig. 4)}

Mitochondrial function is assessed by comparing the rate of oxidative ATP synthesis (conveniently assessed at the end of exercise by the initial rate of PCr resynthesis [10]) with a driving force. In Fig. 4A this force is the end-exercise fall in $\mathrm{PCr}$, which is the simplest error signal and a convenient surrogate for possible others. The linear relationship over 50\% and 75\% MVC exercise implies a near-invariant $\mathrm{PCr}$ recovery rate constant (the slope of the line), and is consistent with closed-loop feedback [5,6]. In aerobic exercise this slope is taken to reflect 'mitochondrial capacity', i.e., the oxidative ATP synthesis rate extrapolated to 'complete' PCr depletion [47]. Figure 4A shows that mitochondrial capacity is decreased in patients, so that at 50\% MVC a normal rate of $\mathrm{PCr}$ resynthesis is achieved only at the expense of an 


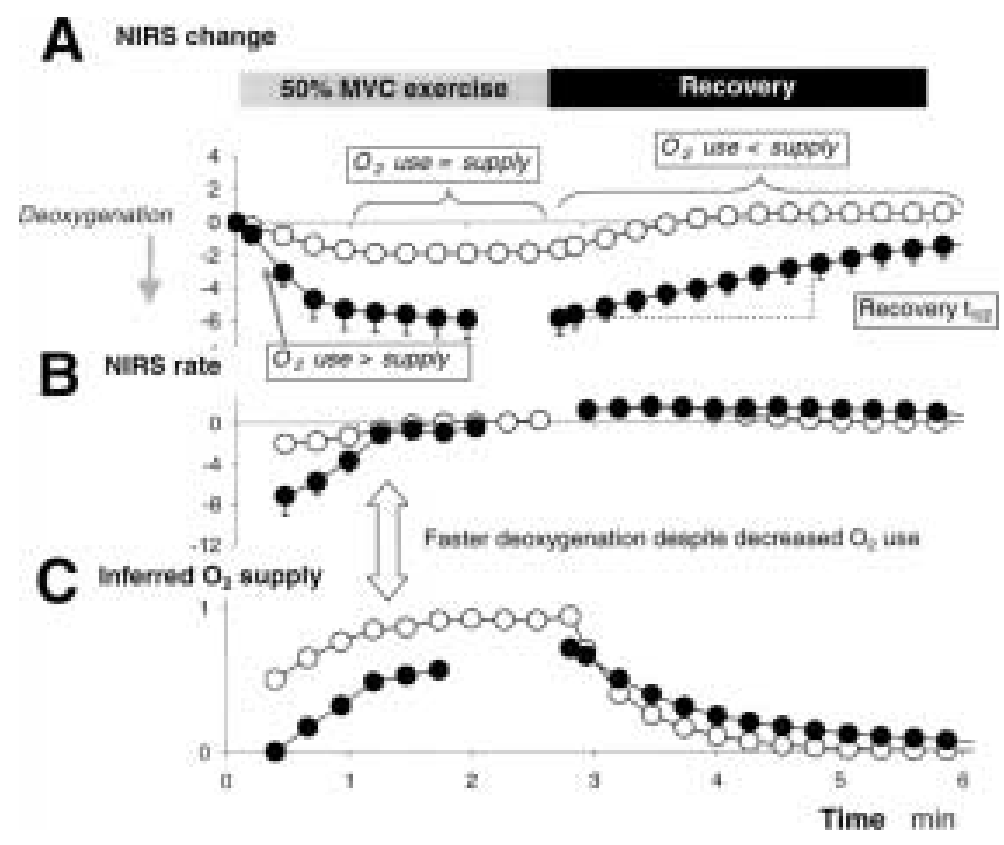

Fig. 3. NIRS changes during exercise and recovery. This figure combines observed changes in NIRS signal (panel A), rates of change of NIRS (panel B) and inferred rates of net $\mathrm{O}_{2}$ delivery (Panel C) during exercise at $50 \% \mathrm{MVC}$ and subsequent recovery, together with labels describing the principles of analysis. Results are mean \pm SEM for patients (solid circles) and control subjects (open circles), shown in composite presentations as in Fig. 2. In order to reduce inter-person variability, NIRS falls are expressed here after correction for ATP turnover rate, the greatest contributor to such variation [24]. (A) shows the change from baseline of the NIRS signal (arbitrary units, baseline $=0$ ). During exercise deoxygenation occurs because mitochondrial $\mathrm{O}_{2}$ use exceeds vascular $\mathrm{O}_{2}$ supply [25,125], until they equalise at steady state. In recovery, $\mathrm{O}_{2}$ use (for resynthesis of $\mathrm{PCr}$ ) declines faster than $\mathrm{O}_{2}$ supply, and oxygenation increases back to basal or beyond. When vascular $\mathrm{O}_{2}$ supply is defective, as here, there is increased deoxygenation during exercise and slow recovery. By contrast, when mitochondrial function is intrinsically defective (e.g., mitochondrial myopathy), there may be reduced deoxygenation [126], or even hyperoxygenation [127]. (B) shows rate of NIRS, calculated by a running linear regression analysis from the data in Panel A. (C) shows inferred rates of net $\mathrm{O}_{2}$ delivery, expressed as 'ATP-units', calculated from the data shown in Panel (B) and Fig. 2C. This is a somewhat schematic analysis, and its precise definition awaits more rigorously quantified experiments, but it shows how the defect in net oxygen supply must exceed that in oxygen consumption (filled circles in Fig. 2B), because deoxygenation is increased (panel A).

increased $\mathrm{PCr}$ change. The patients also seem to miss an opportunity for additional $\mathrm{PCr}$ change at $75 \%$ MVC. But here the aerobic paradigm breaks down: Fig. 4B (which plots initial rate of PCr resynthesis against ATP turnover rate) shows that in controls essentially all ATP turnover is oxidative, but at $75 \%$ MVC patients have a substantial glycolytic contribution $(0.25 \pm 0.08$ and $0.30 \pm 0.07$ of total ATP turnover in patients at the end of exercise at 50\% and $75 \% \mathrm{MVC}$, respectively). The control of this component is poorly understood, although as $\mathrm{pH}$ change is small [24] and linearity preserved (Fig. 4A), this should not affect the 'linear-model' interpretation [8] of the PCr rate constant.

Different analyses are illustrated (see Section 2.5) in Figs 4C \& D, which show initial PCr resynthesis rate against end-exercise [ADP] and $\Delta G_{\mathrm{ATP}}$, respectively, together with the fitted curves. In both cases the inset plots show the relationships extended to very high $x$-values (near-complete PCr depletion). Any of these analyses [48,49] are useful in assessing changes in disease, although they do not agree numerically: apparent mitochondrial capacity is reduced to $0.68 \pm 0.07$ of control on the ADP-control model (Fig. 4C), and $0.61 \pm 0.11$ of control on the 'thermodynamic model' (Fig. 4D), compared to $0.46 \pm 0.05$ on the linear model (Fig. 4A). These numbers, and the implied absolute maximum rates, 
Initial $\mathrm{PCr}$ resynthesis rate $=$ oxidative ATP synthesis rate
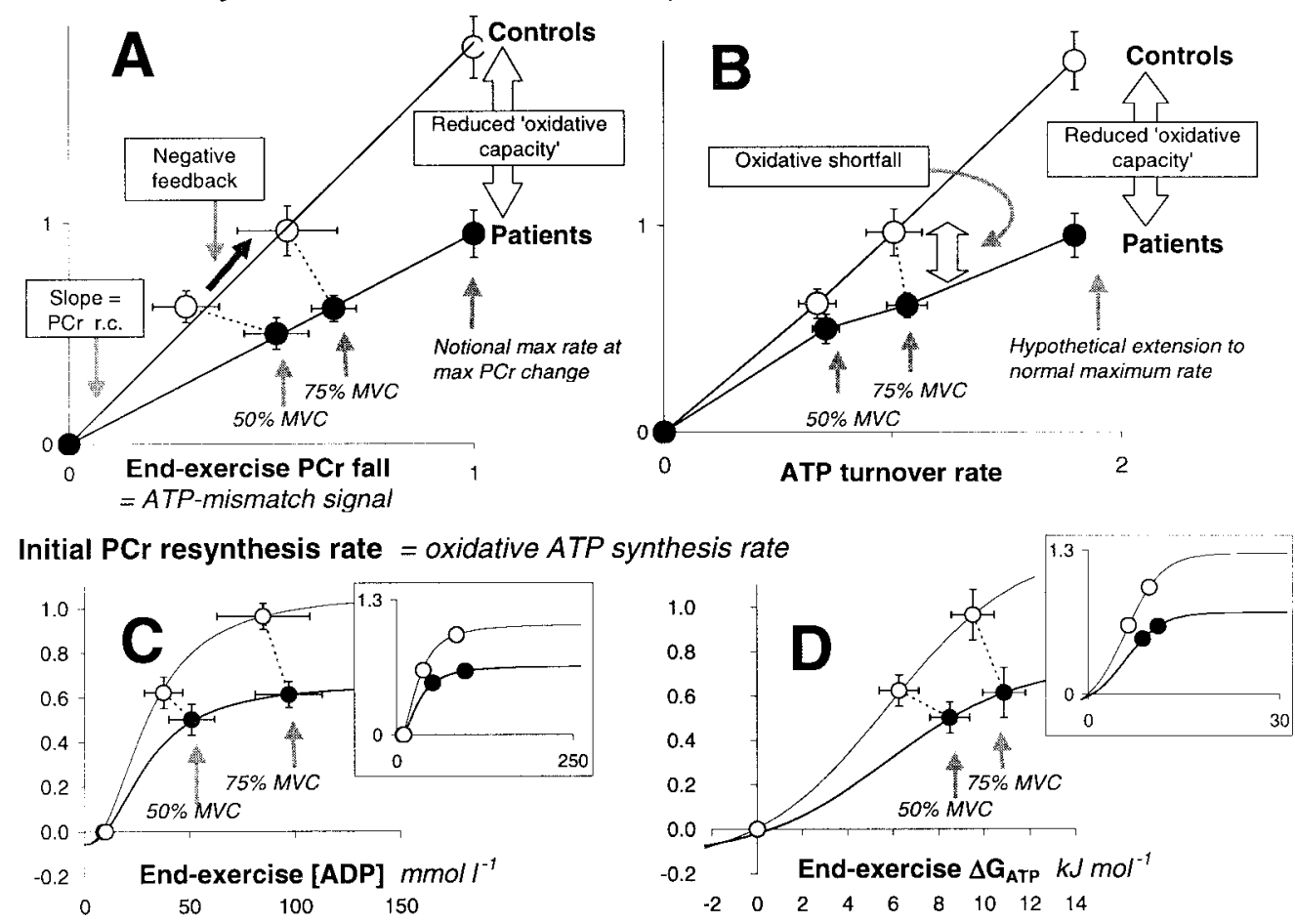

Fig. 4. PCr recovery data and principles of analysis (see Section 2.5). (A) shows initial PCr resynthesis rate (= end-exercise oxidative ATP synthesis rate) at 50\% and 75\% MVC as a function of the end-exercise fall in PCr below basal (the 'ATP-mismatch' signal); both are expressed relative to resting [PCr]. Increased ATP demand from 50-75\% MVC results in increased $\triangle \mathrm{PCr}$ (and related signals), and consequent feedback increase in ATP synthesis. In recovery the workload is removed and ATP demand is near-zero, and both signal and rate return to basal (i.e., the origin). The details of this are debated, but the largely aerobic exercise studied here is not controversial [8] (see Sections $4.2 \& 4.3$ ): the reduction in oxidative function is reflected in the reduced slope of the fitted line, the PCr recovery rate constant. This relationship is also used to estimate oxidative ATP synthesis rate in exercise. (B) shows oxidative ATP synthesis rate plotted against ATP turnover rate. It can be seen that in controls essentially all ATP turnover is oxidative, but at $75 \%$ MVC patients have a substantial glycolytic contribution.(C) and (D) show, in a similar form to Panel A, initial PCr resynthesis rate at $50 \%$ and $75 \% \mathrm{MVC}$ as a function of the end-exercise [ADP] and $\Delta G_{\text {ATP }}$ respectively (other ATP-mismatch signals), fitted with the sigmoid relationship described in Section 2.5. The inset shows the same plot extrapolated to substantial PCr depletion (at 'complete' PCr depletion - corresponding to the rightmost points in Panel A - both are infinite).

are of course parameter-dependent, and it is not yet possible to decide between them. It also remains to be shown how these analyses relate to the exercise physiologists' $V_{\mathrm{O}_{2 \max }}$ i.e., $\mathrm{O}_{2}$ consumption in peak exercise $[22,50]$.

\section{4. $\mathrm{PO}_{2}$ and oxidative ATP synthesis rate (Fig. 5)}

It is of interest to ask how oxidative ATP synthesis rate is related to cellular $\mathrm{PO}_{2}$. We can take initial $\mathrm{PCr}$ resynthesis rate as a measure of the former, and NIRS gives us some information on the later. A simple plot of one against the other (Fig. 5A) shows how in controls at 75\% MVC (compared to 50\% $\mathrm{MVC}$ ) the higher rate of $\mathrm{PCr}$ resynthesis occurs despite the greater cellular deoxygenation represented by the larger NIRS change. We argue that the higher $\mathrm{PCr}$ resynthesis rate is driven by the $\mathrm{PCr}$ changes (or equivalent changes in ADP or $\Delta G_{\mathrm{ATP}}$ ), and not limited by the lower cellular $\mathrm{PO}_{2}$. In patients the rate 

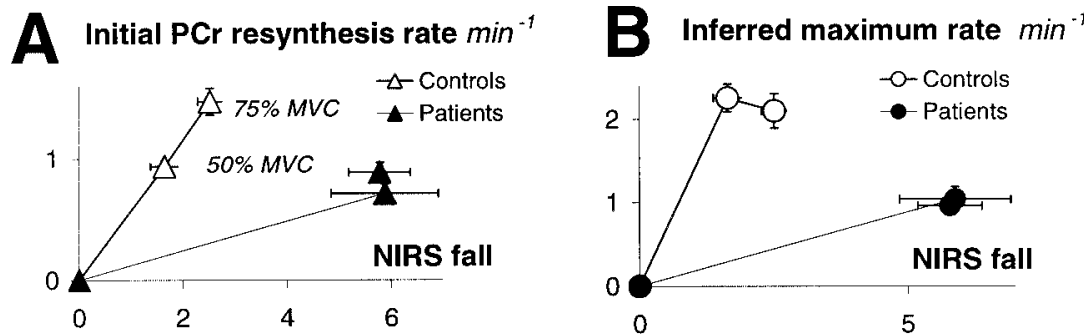

C Initial $\mathrm{PCr}$ resynthesis rate \& inferred maximum rate $\min ^{-1}$

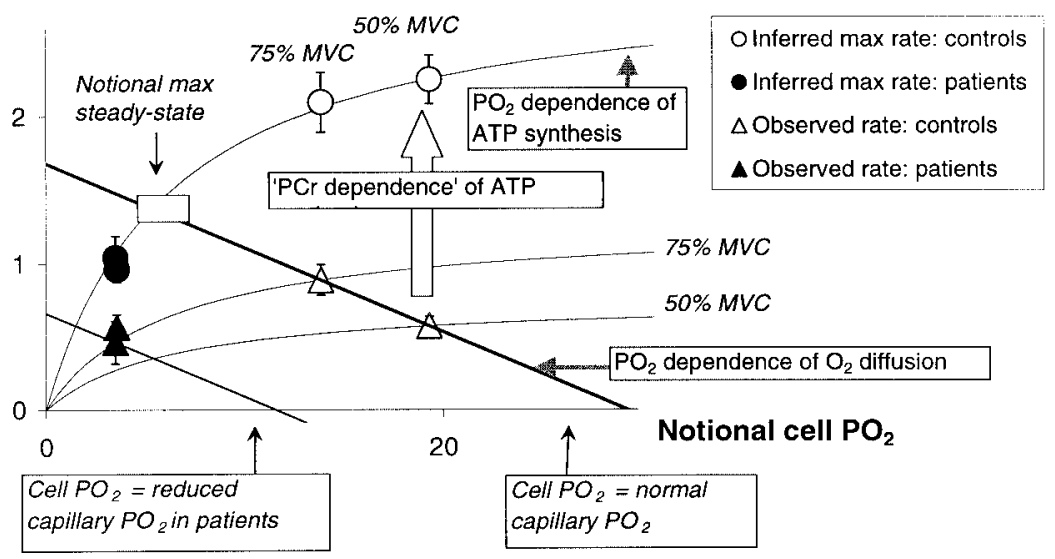

Fig. 5. Oxidative ATP synthesis and cellular oxygenation (see Section 2.6). (A) shows (triangles) the initial post-exercise PCr resynthesis rate $(\approx$ end-exercise oxidative ATP synthesis rate) as a function of the below-basal fall in NIRS. This contains information about the relationship between oxidative ATP synthesis rate and cellular $\mathrm{PO}_{2}$, but the latter is concealed in the NIRS data and the former is complicated by the effects of altered concentrations of PCr and other ATP-mismatch signals. (B) takes the analysis a stage further, controlling for the effect of altered ATP-mismatch signals by plotting the PCr recovery rate constant (circles) against NIRS change. (C) goes one more step by converting the NIRS data into an estimate (at this stage very rough) of cellular $\mathrm{PO}_{2}$, against which we plot both oxidative ATP synthesis rate (triangles) and the inferred maximum rate of oxidative synthesis (circles). This resembles plots of maximal oxygen consumption [50] against cellular $\mathrm{PO}_{2}$ derived from ${ }^{1} \mathrm{H}$ MRS measurements of deoxymyoglobin, and because both rates are expressed here relative to resting [PCr], the inferred maximum rate is simply the $\mathrm{PCr}$ recovery rate constant $k$, as in [47]. The hyperbolic lines represent the notional $\mathrm{O}_{2}$-dependence of cytochrome oxidase activity, and their shape is defined by the maximal-rate points at 50\% and $75 \% \mathrm{MVC}$ exercise: this is a rather schematic curve, and more work at lower $\mathrm{PO}_{2}$ will be required to define this. The broad upward arrow indicates schematically how, at a given $\mathrm{O}_{2}$, oxidative ATP synthesis rate increases when PCr falls (and ADP increases, etc.) this corresponds to movement along the curve in Figs 4A, C \& D. This too is schematic, as there is no detailed work on the interactions between $\mathrm{PO}_{2}$ and $\mathrm{PCr}$ change. The diagonal lines show how cellular hypoxia enhances $\mathrm{O}_{2}$ diffusion from capillary to mitochondrion [50]; their slope is the cellular $\mathrm{O}_{2}$ diffusion capacity [123], and $\mathrm{O}_{2}$ flux is zero when cell and capillary $\mathrm{PO}_{2}$ are the same (intercept on x-axis) and maximal when cell $\mathrm{PO}_{2}$ is zero (intercept on $y$-axis). However, nonzero $\mathrm{PO}_{2}$ is required to drive cytochrome oxidase, and so the steady-state (arrowed square) occurs when the (diagonal) diffusion line and (hyperbolic) 'mitochondrial' lines intersect [50]. In this figure the slope of the line is defined by the 50\% and 75\% MVC data points, and assumed to be the same in patients and controls (not true, for example, in chronic renal failure [123]). The patients operate at much lower $\mathrm{PO}_{2}$, and this causes lower oxidative ATP synthesis rates, partly compensated for by increased $\mathrm{PCr}$ change.

is lower and the deoxygenation is greater, despite the greater change in $\mathrm{PCr}$; this is consistent with $\mathrm{PO}_{2}$ limiting the rate in a way which is not compensated by increased $\mathrm{PCr}$ (although it might be if this were permitted). Figure 5B accounts for the extra CK-system drive by plotting the $\mathrm{PCr}$ recovery rate constant (as a measure of 'mitochondrial capacity' at a given $\mathrm{PO}_{2}$ ) against NIRS change. To a first approximation this is independent of cellular deoxygenation in controls (in patients one cannot tell). 
To take this further we must consider the interactions between $\mathrm{PO}_{2}$ and the error signals (of which we take $\mathrm{PCr}$ as representative). In experimental hypoxia larger changes in, e.g., $\mathrm{PCr}$ are required for a given $V_{\mathrm{O}_{2}}$, suggesting that different oxygen conditions result in a family of transfer functions [51]. Thus, like reduction in mitochondrial content [49], experimental hypoxia results in a 'scaled-down' curve [51]. Figure $5 \mathrm{C}$ extends this analysis to the present case of cellular hypoxia due to impaired blood flow. Whether or not NIRS signals indeed reflect myoglobin-associated (cellular) $\mathrm{PO}_{2}$ [23] rather than haemoglobinrelated (capillary) $\mathrm{PO}_{2}$, the larger NIRS changes in patients [24] imply a lower cell and capillary $\mathrm{PO}_{2}$, and this, via the $\mathrm{PO}_{2}$-dependence of cytochrome oxidase, is presumably responsible for the mitochondrial dysfunction implied by Fig. 5C. The power-dependent NIRS change seen in both patients and controls ([24] conflicts with the power-independence of myoglobin-associated $\mathrm{PO}_{2}$ in quadriceps [22], a finding which itself raises interesting questions (see Section 4.5).

\section{Discussion}

\subsection{Interpretation of $\mathrm{PCr}$ changes in exercise}

Changes in PCr during exercise are one of the most basic ${ }^{31} \mathrm{P}$ MRS measurements. The change in $\mathrm{PCr}$, first, registers algebraically the time-integrated amount by which ATP production fails to keep up with supply. Second, it reflects the amount by which the CK system has to be perturbed in order to drive ATP synthesis. In exercise of this kind we are concerned mainly with oxidative ATP synthesis, where ADP has often been considered the causally effective part of the system (see above). Thus in a disease state an increase in PCr change (as here) implies increased bioenergetic 'strain', due either to increased energy demands (increased metabolic 'stress'), or to inadequate oxidative ATP synthesis (metabolic 'weakness'). Of these, we can rule out increased ATP demand because force, contractile efficiency and ATP turnover are all normal. The defect lies in oxidative ATP synthesis, as evidenced by slow post-exercise $\mathrm{PCr}$ recovery, which depends both on intrinsic mitochondrial function and (contrary to what is sometimes assumed [52]) on vascular $\mathrm{O}_{2}$ supply.

\subsection{Mitochondrial regulation}

In vitro mitochondrial respiration rate bears a hyperbolic relationship to [ADP] with $\mathrm{Km}$ values of 20 $30 \mu \mathrm{moll}^{-1}$ [53,54] classically, although lower values are reported [55-57]. ${ }^{31} \mathrm{P}$ MRS provides much evidence for a similar relationship in vivo, for example, in aerobic exercise using steady-state power output [7,45], $\mathrm{O}_{2}$ consumption [58,59] or the Pi-to-ATP flux measured by MR saturation transfer [60] as measures of oxidative ATP synthesis rate, and in recovery using an analysis like that of Fig. 4C [10,37, $48,49,61]$. This, together with the relative insensitivity of ATP use to [ADP], at least in moderate exercise [30], is the basis of the ADP-feedback model of mitochondrial control [2,6,7]. However, a strictly hyperbolic relationship to [ADP] makes insufficient allowance for the whole dynamic range from rest to maximal rates $[9,62]$, and one solution to this (followed in Fig. 4C) is to fit a sigmoid relationship with Hill coefficient around 2-3 [9,43]. There is disagreement about whether this is sufficient, or valid $[5,9,62-$ 64], but it has some recent support from reports of a direct effect of mitochondrial ADP on cytochrome oxidase activity [19]. This is not the whole story. There is no explanation of 'overshoots' in PCr [58] and ADP [27] during recovery, or of some anomalous relationships in exercising muscle in experimental acidosis [10] or pharmacological ATP-depletion [65]. However, some earlier arguments against the ADP control model [66-68] rest heavily [1,69] on implausibly high estimates of resting [ADP]. 
There are other candidates for the transfer function relating oxidative ATP synthesis rate to its regulatory signal. As Fig. 4 illustrates, the creatine kinase equilibrium [6,29] ensures that, for modest changes in $\mathrm{pH}$, oxidation rate correlates with several possible feedback signals [6], giving most notably a linear relationship with [PCr] concentration $[8,17,37,48,68]$ (we discuss elsewhere [4] the relationship of this to the classical phosphocreatine shuttle hypothesis [68]), and a sigmoid relationship to $\Delta G_{\text {ATP }}$, also seen in isolated mitochondria in vitro [57,70]. In muscle during experimental acidosis [10] and when mitochondrial content is experimentally manipulated [49] this model offers more invariant flux-signal relationship, or at least one that varies more explicably, than the ADP-control model. This is currently the subject of debate.

We discuss elsewhere [4] the relationships between these feedback-based approaches and the more general approaches of Metabolic Control Analysis, which has been used in vitro [71], and phenomenological nonequilibrium thermodynamics, which has been applied both in vivo [72] and in vitro [70], and also to models incorporating diffusion of metabolites [3,4,73]. Aerobic exercise lends itself readily to simulation approaches. The linear steady-state correlations with [PCr] imply exponential kinetics $[6,66]$, vice versa [6,68]. The same is true of the partially-linear relationship to $\Delta G_{\mathrm{ATP}}[6,8]$. These analyses neglect changes in [ATP] which are not seen in the present experiments, but can be incorporated into both linear [66] and ADP-control models [73]. Lastly, attempts have been made to avoid assuming that creatine kinase is necessarily at equilibrium, and to allow for possible roles of mitochondrial creatine kinase $[4,74,75]$.

\subsection{Measuring mitochondrial function}

It is uncontroversial that analysis of PCr recovery yields information about mitochondrial function [27, 48]. We have seen how candidate measures of the maximum rate of oxidative ATP synthesis can be obtained from the ADP control model (Fig. 4C) and the thermodynamic model (Fig. 4D). The rate constant of PCr recovery (Fig. 4A) has also long been used. However, it is known to decrease (i.e., the halftime to increase) with decreasing end-exercise $\mathrm{pH}$ [27,76-81]. This relationship can be used to identify clinical departures from normal [77,82], but an advantage of the ADP-control model is that this is accounted for by the relationship between $\mathrm{pH}$ and [ADP] rather than a (probably implausible) change in mitochondrial properties [81]. When $\mathrm{pH}$ falls substantially $\mathrm{PCr}$ recovery becomes 'biphasic' (i.e., biexponential) $[27,83,84]$, and alternative descriptions have been advocated [85], which achieve a good experimental fit by using parameters with no obvious physiological interpretation.

Using various of these measures, there is, as expected, a good relationship between mitochondrial content and aerobic capacity in comparative studies [86] and between muscles of differing fibre type content [87]. Furthermore PCr recovery is slowed in primary mitochondrial disease [88-90] and in some migraine disorders [91,92]; where mitochondrial content or function is reduced, e.g., cardiac failure [93,94], experimental cardiac infarction [37,95] and disuse atrophy [96]. The case of dialysed uraemic patients is controversial as there is evidence of slow PCr recovery [88,97-99], but with a number of possible causes [100]. PCr recovery is enhanced by endurance training $[49,101,102]$ and chronic muscle stimulation [87,103], consistent with increased mitochondrial content, maximal $\mathrm{O}_{2}$ consumption and enzyme activities. PCr recovery correlates with mitochondrial content (三 citrate synthase activity) in aging muscle [104] and various experimental manipulations [49]. As well as in peripheral vascular disease, $\mathrm{PCr}$ recovery is slowed in other human disease affecting vascular $\mathrm{O}_{2}$ delivery, including myelodysplastic anaemia [88,105] and cyanotic heart disease [88,106], and in experimental iron deficiency [107]. In exercise-trained normal subjects made hypoxic, both $V_{\mathrm{O}_{2} \text { max }}$ [22] and $\mathrm{PCr}$ recovery rate constant [47] are 
decreased, although the opposite effect in hyperoxia is less marked: this together with ${ }^{1} \mathrm{H}$ MRS measurements of cellular $\mathrm{PO}_{2}$ suggest the roughly hyperbolic relationship between $V_{\mathrm{O}_{2} \text { max }}$ and cellular $\mathrm{PO}_{2}$ of which we give a version as the upper line in Fig. 5C [22,47].

\subsection{Deoxygenation and ATP turnover}

${ }^{1} \mathrm{H}$ MRS deoxymyoglobin measurements have shown that cellular $\mathrm{PO}_{2}$ is much smaller than capillary $\mathrm{PO}_{2}$, and thus that $\mathrm{PO}_{2}$ cannot be ruled out as a 'limiting factor' in oxidative ATP synthesis [22]. However these studies [22] show constant $\mathrm{PO}_{2}$ over exercise from 50-100\% $V_{\mathrm{O}_{2} \text { max }}$ in human quadriceps in normoxia, and a similar constancy at a lower $\mathrm{PO}_{2}$ in hypoxia. By contrast, we find that NIRS signal increases from 50 to $75 \%$ MVC (Fig. 5A). There is no simple way to compare the metabolic stress of these two kinds of exercise (dynamic knee extension vs isometric plantarflexion), but our 50-75\% $\mathrm{MVC}$ range corresponds on the linear model of mitochondrial control to $35-55 \% V_{\mathrm{O}_{2} \text { max }}$ in controls, $110-160 \% V_{\mathrm{O}_{2} \max }$ in patients. It may be, therefore, that exercise intensity in our experiments may be both too low (in controls) and too high (in patients) to manifest this constant cell oxygenation state. For patients, indeed, deoxygenation seems near-complete at $75 \%$ MVC, and not much less so at 50\% MVC (it would be predicted, then, that glycolytic ATP production would soon become dominant at $75 \% \mathrm{MVC}$ in patients). This difference might also be related to ill-understood physiological differences between the NIRS and ${ }^{1} \mathrm{H}$ MRS signals, or to the different protocols. There is a report [108] of progressive reduction of cytochrome aa3 with increasing exercise intensity in canine gracilis, this being almost complete in maximal exercise; if this reflects near-mitochondrial $\mathrm{PO}_{2}$ it implies a very low $\mathrm{Km}$ for the hyperbolic curves in Fig. 4C. It has been suggested [22] that preservation of myoglobin-associated $\mathrm{PO}_{2}$ despite this reduction of cytochrome aa3 reflects finite $\mathrm{O}_{2}$ diffusion from cytosol to mitochondria (cf capillary $\mathrm{PO}_{2}$ at $V_{\mathrm{O}_{2} \max }$, driving $\mathrm{O}_{2}$ from capillary to cytosol). This would make both NIRS and ${ }^{1} \mathrm{H}$ MRS measurements an unsuitable basis for the $\mathrm{x}$-axis in Fig. $4 \mathrm{C}$, which attempts to related flux to mitochondrial $\mathrm{PO}_{2}$. Nevertheless we argue that the schema remains useful.

The $\mathrm{PO}_{2}$-dependence of maximum oxidative ATP synthesis has been studied in experimental hypoxia $[22,47]$. Fig. $5 \mathrm{C}$, which plots oxidative ATP synthesis rate against notional cell $\mathrm{PO}_{2}$, extends the analysis, somewhat schematically, to incorporate the ATP-turnover error signal (represented by PCr). Increasing PCr perturbation can partially outweigh hypoxia [47] (Fig. 4A), and true maximum flux would seem to require maximum PCr change (upward arrow in Fig. 5C), at least within the limits of ADPinhibition of ATPase [30]. Figure 5C also shows how cellular hypoxia enhances $\mathrm{O}_{2}$ diffusion from capillary to mitochondrion [22], the steady-state occurring when the (diagonal) diffusion line and (hyperbolic) 'mitochondrial' lines intersect. Thus inferences from rate-signal relationships may overstate maximum rates, at least at steady state, because of the need for lower $\mathrm{PO}_{2}$ to sustain $\mathrm{O}_{2}$ diffusion (arrowed square in Fig. 5C): the size of this effect depends on the shape of these curves, which is not well-defined. The patients operate at much lower $\mathrm{PO}_{2}$, and this causes lower oxidative ATP synthesis rates, partly compensated for by increased $\mathrm{PCr}$ change; we cannot yet test whether this is a complete explanation.

\section{Appendix: absolute metabolite concentrations}

This is still a controversial subject. We follow some of the calf muscle ${ }^{31} \mathrm{P}$ MRS literature $[16,109$ 111] in setting resting [PCr] at $35 \mathrm{mmol}^{-1}$, and similar values are reported in forearm muscle [11, $16,33,97]$; however other calf muscle studies report values $\approx 30 \mathrm{mmoll}^{-1}$ by biopsy [112,113] and $\approx 22-30 \mathrm{mmoll}^{-1}$ by various ${ }^{31} \mathrm{P}$ MRS methods [61,114-119]. Our resting [ADP] of $10 \mu \mathrm{mol} \mathrm{l}^{-1}$ is 
comparable to other ${ }^{31} \mathrm{P}$ MRS studies of calf $[16,109-111,120]$ and forearm muscle $[9,16,45,121]$, and the resting $\Delta G_{\text {ATP }}$ of $-62 \mathrm{~kJ} \mathrm{~mol}^{-1}$ is fairly close to other reports in calf [120] and forearm [9]. None of the present findings depend critically on these uncertainties.

\section{Acknowledgements}

We are grateful to Pfizer Global Research and Development, Sandwich, UK for supporting the experimental portion of this work.

\section{References}

[1] G.J. Kemp and G.K. Radda, Magn. Reson. Quart. 10 (1994), 43-63.

[2] M.J. Kushmerick and K.E. Conley, Biochem. Soc. Trans. 30 (2002), 227-231.

[3] R.A. Meyer, H.L. Sweeney and M.J. Kushmerick, Am. J. Physiol. 246 (1984), C365-C377.

[4] G.J. Kemp, D.N. Manners, M.E. Bastin, J.F. Clark and G.K. Radda, Mol. Cell. Biochem. 184 (1998), 249-289.

[5] G.J. Kemp, Biochem. Soc. Trans. 28 (2000), 100-103.

[6] G.J. Kemp, J. Theor. Biol. 170 (1994), 239-246.

[7] B. Chance, J. Leigh Jr, B.J. Clark, J. Maris, J. Kent, S. Nioka and D. Smith, Proc. Natl. Acad. Sci. USA 82 (1985), 8384-8388.

[8] R.A. Meyer, Am. J. Physiol. 254 (1988), C548-C553.

[9] J.A.L. Jeneson, R.W. Wiseman, H.V. Westerhoff and M.J. Kushmerick, J. Biol. Chem. 271 (1996), $27995-27998$.

[10] S.J. Harkema and R.A. Meyer, Am. J. Physiol. 272 (1997), C491-500.

[11] K.E. Conley, M.L. Blei, T.L. Richards, M.J. Kushmerick and S.A. Jubrias, Am. J. Physiol. 273 (1997), C306-C315.

[12] G.J. Kemp, M. Roussel, D. Bendahan, Y. Le Fur and P.J. Cozzone, J. Physiol. 535 (2001), 901-928.

[13] J.M. Foley and R.A. Meyer, NMR Biomed. 6 (1993), 32-38.

[14] G. Kemp, C. Thompson, D. Taylor and G. Radda, Eur. J. Appl. Physiol. 5 (1997), 462-471.

[15] G.J. Kemp, C.H. Thompson, A.L. Sanderson and G.K. Radda, Magn. Reson. Med. 31 (1994), 103-109.

[16] K.E. Conley, M.J. Kushmerick and S.A. Jubrias, J. Physiol. 511 (1998), 935-945.

[17] R.A. Meyer, Am. J. Physiol. 257 (1989), C1149-C1157.

[18] P.D. Wagner, Ann. Rev. Physiol. 58 (1996), 21-50.

[19] S. Arnold and B. Kadenbach, FEBS Lett. 443 (1999), 105-108.

[20] R. Boushel and C.A. Piantadosi, Acta Physiol. Scand. 168 (2000), 615-622.

[21] K.E. Conley and C. Jones, Am. J. Physiol. 271 (1996), C2027-2036.

[22] R.S. Richardson, J.S. Leigh, P.D. Wagner and E.A. Noyszewski, J. Appl. Physiol. 87 (1999), 325-331.

[23] T.K. Tran, N. Sailasuta, U. Kreutzer, R. Hurd, Y. Chung, P. Mole, S. Kuno and T. Jue, Am. J. Physiol. 276 (1999), R1682-1690.

[24] G.J. Kemp, N. Roberts, W.E. Bimson, A. Bakran, P.L. Harris, G.L. Gilling-Smith, J. Brennan, A. Rankin and S.P. Frostick, J. Vasc. Surg. 34 (2001), 1103-1110.

[25] A. Hanada, K. Okita, K. Yonezawa, M. Ohtsubo, T. Kohya, T. Murakami, H. Nishijima, M. Tamura and A. Kitabatake, Heart 83 (2000), 161-166.

[26] Q. Gong, J. Phoenix, G. Kemp, M. García-Fiñana, S. Frostick, D. Brodie, R. Edwards, G. Whitehouse and N. Roberts, J. Magn. Reson. Imag. (2000), 467-475.

[27] D.L. Arnold, P.M. Matthews and G.K. Radda, Magn. Reson. Med. 1 (1984), 307-315.

[28] R.C. Harris, E. Hultman and L.-O. Nordesjo, Scand. J. Lab. Clin. Invest. 33 (1974), 109-120.

[29] R. Connett, Am. J. Physiol. 254 (1988), R949-R959.

[30] J.A. Jeneson, H.V. Westerhoff and M.J. Kushmerick, Am. J. Physiol. 279 (2000), C813-832.

[31] J. Bangsbo, T.E. Graham, B. Kiens and B. Saltin, J. Physiol. 451 (1992), 205-227.

[32] S.J. Harkema, G.R. Adams and R.A. Meyer, Am. J. Physiol. 272 (1997), C485-C490.

[33] M.L. Blei, K.E. Conley and M.J. Kushmerick, J. Physiol. 465 (1993), 203-222.

[34] M.T. Crow and M.J. Kushmerick, J. Gen. Physiol. 79 (1982), 147-166.

[35] D.J. Newham, D.A. Jones, D.L. Turner and D. McIntyre, J. Physiol. 488 (1995), 815-819.

[36] T.W. Ryschon, M.D. Fowler, R.E. Wysong, A. Anthony and R.S. Balaban, J. Appl. Physiol. 83 (1997), 867-874.

[37] C.H. Thompson, G.J. Kemp, A.L. Sanderson and G.K. Radda, J. Appl. Physiol. 78 (1995), 2131-2139.

[38] J. Bangsbo, P.D. Gollnick, T.E. Graham, C. Juel, B. Kiens, M. Mizuno and B. Saltin, J. Physiol. 422 (1990), 539-559. 
[39] G.J. Crowther, W.F. Kemper, M.F. Carey and K.E. Conley, Am. J. Physiol. 282 (2002), E74-79.

[40] B. Quistorff, L. Johansen and K. Sahlin, Biochem. J. 291 (1993), 681-686.

[41] F. Lou, W.J. van Der Laarse, N.A. Curtin and R.C. Woledge, J. Exp. Biol. 203 (2000), 1201-1210.

[42] G. Walter, K. Vandenborne, K.K. McCully and J.S. Leigh, Am. J. Physiol. 272 (1997), C525-C534.

[43] J.H. Cieslar and G.P. Dobson, J. Biol. Chem. 275 (2000), 6129-6134.

[44] H.V. Westerhoff, C.J. van Echteld and J.A. Jeneson, Biophys. Chem. 54 (1995), 137-142.

[45] J.A.L. Jeneson, H.V. Westerhoff, T.R. Brown, C.J.A. van Echteld and R. Berger, Am. J. Physiol. 268 (1995), C1474C1484.

[46] R. Van der Meer, H.V. Westerhoff and K. vanDam, Biochim. Biophys. Acta 691 (1980), 488-493.

[47] L.J. Haseler, M.C. Hogan and R.S. Richardson, J. Appl. Physiol. 86 (1999), 2013-2018.

[48] G.J. Kemp, D.J. Taylor and G.K. Radda, NMR Biomed. 6 (1993), 66-72.

[49] A.T. Paganini, J.M. Foley and R.A. Meyer, Am. J. Physiol. 272 (1997), C501-C510.

[50] R.S. Richardson, B. Grassi, T.P. Gavin, L.J. Haseler, K. Tagore, J. Roca and P.D. Wagner, J. Appl. Physiol. 86 (1999), 1048-1053.

[51] M.C. Hogan, R.S. Richardson and L.J. Haseler, J. Appl. Physiol. 86 (1999), 1367-1373.

[52] G.E. Moore, L.A. Bertocci and P.L. Painter, J. Clin. Invest. 91 (1993), 420-424.

[53] B. Chance and G.R. Williams, J. Biol. Chem. 217 (1955), 409-427.

[54] B. Chance and J. Williams, Adv. Enzymol. 17 (1956), 65-134.

[55] V.A. Saks, A.V. Kuznetsov, Z.A. Khuchua, E.V. Vasilyeva, J.O. Belikova, T. Kesvatera and T. Tiivel, J. Mol. Cell. Cardiol. 27 (1995), 625-645.

[56] W.E. Jacobus, R.W. Moreadith and K.M. Vandergaer, Ann. NY Acad. Sci. 414 (1983), 77-89.

[57] L. Gyulai, Z. Roth, J.S. Leigh and B. Chance, J. Biol. Chem. 260 (1985), 3947-3954.

[58] M.J. Kushmerick, R.A. Meyer and T.R. Brown, Am. J. Physiol. 263 (1992), C598-C605.

[59] S. Nioka, Z. Argov, G.P. Dobson, R.E. Forster, H.V. Subramanian, R.L. Veech and B. Chance, J. Appl. Physiol. 72 (1992), 521-528.

[60] K.M. Brindle, M.J. Blackledge, R.A.J. Challis and G.K. Radda, Biochemistry 28 (1989), 4887-4893.

[61] M. Boska, Magn. Reson. Med. 32 (1994), 1-10.

[62] B. Korzeniewski, Biochem. J. 330 (1998), 1189-1195.

[63] J.A. Jeneson, R.W. Wiseman, M.J. Kushmerick and H.V. Westerhoff, Am. J. Physiol. 275 (1998), H726-728.

[64] M.A. Portman, Y. Xiao, Y. Song and X.H. Ning, Am. J. Physiol. 273 (1997), H1977-H1983. [See comments: J.A. Jeneson, R.W. Wiseman, M.J. Kushmerick and H.V. Westerhoff, Am. J. Physiol. 127(5) (1998), H1726-H1728.]

[65] J.F. Foley, S.J. Harkema and R.A. Meyer. Am. J. Physiol. 261 (1991), C872-C881.

[66] C.I. Funk, A. Clark and R.J. Connett, Am. J. Physiol. 258 (1990), C995-C1005.

[67] R.J. Connett and C.A. Honig, Am. J. Physiol. 256 (1989), R898-R906.

[68] M. Mahler, J. Gen. Physiol. 86 (1985), 135-165.

[69] B. Chance and K. LaNoue, Am. J. Physiol. 257 (1989), R288-R290.

[70] R.A.J. Wanders and H.V. Westerhoff, Biochemistry 27 (1988), 7832-7840.

[71] R.P. Hafner, G.C. Brown and M. Brand, Eur. J. Biochem. 188 (1990), 313-319.

[72] J.W. Stucki, Proc. Roy. Soc. Lond. B 244 (1991), 197-202.

[73] H.L. Sweeney, Med. Sci. Sports Exerc. 26 (1994), 30-36.

[74] M.J. Kushmerick, Comp. Biochem. Physiol. B Biochem. Mol. Biol. 120 (1998), 109-123.

[75] S.N. Fedosov, Biochim. Biophys. Acta 1208 (1994), 238-246.

[76] D. Bendahan, S. Confort-Gouny, G. Kozak-Reiss and P. Cozzone, FEBS Lett. 272 (1990), 155-158.

[77] B. Barbiroli, P. Montagna, R. Funicello, S. Iotti, L. Monari, G. Pierangeli, P. Zanoli and E. Lugaresi, Neurology 42 (1992), 1209-1214.

[78] S. Iotti, R. Lodi, C. Frassineti, P. Zaniol and B. Barbiroli, NMR Biomed. 6 (1993), 248-253.

[79] K. McCully, S. Iotti, K. Kendrick, Z. Wang, J.D. Posner, J. Leigh and B. Chance, J. Appl. Physiol. 77 (1994), 5-10.

[80] G.J. Kemp, C.H. Thompson, P.R.J. Barnes and G.K. Radda, Magn. Reson. Med. 31 (1994), 248-258.

[81] R. Lodi, G.J. Kemp, S. Iotti, G.K. Radda and B. Barbiroli, MAGMA 5 (1997), 372-378.

[82] B. Barbiroli, P. Montagna, P. Cortelli, S. Iotti, R. Lodi, P. Barboni, L. Monari, E. Lugaresi, C. Frassineti and P. Zaniol, Neurology 45 (1995), 1364-1369.

[83] D.J. Taylor, P. Styles, P.M. Matthews, D.L. Arnold, D.G. Gadian, P.J. Bore and G.K. Radda, Magn. Reson. Med. 3 (1986), 44-54.

[84] R.C. Harris, R.H.T. Edwards, E. Hultman, L.O. Nordesjo, B. Nylind and K. Sahlin, Pflug. Arch. 367 (1976), 137-142.

[85] G.C. Bogdanis, M.E. Nevill, L.H. Boobis, H.K.A. Lakomy and A.M. Nevill, J. Physiol. 482 (1995), 467-480. [See comments: R.A. Meyer, R.W. Wiseman and J.A.L. Jeneson, J. Appl. Physiol. 19(82) (1997), 2169-2171.]

[86] E.R. Weibel, C.R. Taylor, H. Hoppeler and R.H. Karas, Resp. Physiol. 69 (1987), 1-127.

[87] H. Hoppeler, O. Hudlick and E. Uhlmann. J. Physiol. 385 (1987), 661-675. 
[88] G.J. Kemp, C.H. Thompson, D.J. Taylor, L.J. Hands, B. Rajagopalan and G.K. Radda, NMR Biomed. 6 (1993), 302-310.

[89] D.J. Taylor, G.J. Kemp and G.K. Radda, J. Neurol. Sci. 127 (1994), 198-206.

[90] Z. Argov, N. DeStefano and D.L. Arnold. NMR Biomed. 9 (1996), 165-172.

[91] R. Lodi, G.J. Kemp, P. Montagna, P. Cortelli, S. Iotti, G.K. Radda and B. Barbiroli, J. Neurol. Sci. 146 (1997), 73-80.

[92] P. Montagna, R. Lodi, P. Cortelli, G. Pierangeli, S. Iotti, S. Cevoli, P. Zaniol and B. Barbiroli, Neurology 48 (1997), $113-118$.

[93] G.J. Kemp, C.H. Thompson, J.R. Stratton, F. Brunotte, M. Conway, L. Arnolda, G.K. Radda and B. Rajagopalan, Heart 76 (1996), 35-41.

[94] D.M. Mancini, G. Walter, N. Reichek, R. Lenkinski, K.K. McCully, J.L. Mullen and J.R. Wilson, Circulation 85 (1992), $1364-1373$.

[95] C.H. Thompson, G.J. Kemp, B. Rajagopalan and G.K. Radda, Cardiovasc. Res. 29 (1995), 344-349.

[96] N. Yoshida, T. Ikata, K. Sairyo, T. Matsuura, T. Sasa, K. Koga and M. Fukunaga, J. Physiol. Anthropol. Appl. Human Sci. 20 (2001), 247-252.

[97] G.J. Kemp, C.H. Thompson, D.J. Taylor and G.K. Radda, Magn. Reson. Med. 30 (1995), 601-609.

[98] C.H. Thompson, G.J. Kemp, D.J. Taylor, J.G.G. Ledingham, G.K. Radda and B. Rajagopalan, Nephrol. Dial. Transplant. 8 (1993), 218-222.

[99] C.H. Thompson, A. Irish, G.J. Kemp, D.J. Taylor, P. Styles, B. Rajagopalan and G.K. Radda, Clin. Nephrol. 45 (1996), $386-389$.

[100] R.M. Marrades, J. Alonso, J. Roca, J.M. Gonzalez de Suso, J.M. Campistol, J.A. Barbera, O. Diaz, J.V. Torregrosa, J.R. Masclans, R. Rodriguez Roisin and P.D. Wagner, J. Clin. Invest. 97 (1996), 2101-2110.

[101] K.K. McCully, B.P. Boden, M. Tuchler, M.R. Fountain and B. Chance, J. Appl. Physiol. 67 (1989), 926-932.

[102] H. Takahashi, M. Inaki, K. Fujimoto, S. Katsuta, I. Anno, M. Niitsu and Y. Itai, Eur. J. Appl. Physiol. 71 (1995), $396-404$.

[103] K. Schwerzmann, H. Hoppeler, S.R. Kayar and E.R. Weibel, Proc. Natl. Acad. Sci. USA 86 (1989), 1583-1587.

[104] K.K. McCully, R.A. Fielding, W.J. Evans, J.S.J. Leigh and J.D. Posner. J. Appl. Physiol. 75 (1993), 813-819.

[105] C.H. Thompson, G.J. Kemp, D.J. Taylor, J.G.G. Ledingham, G.K. Radda and B. Rajagopalan, Quart. J. Med. 85 (1992), 897-899.

[106] I.T. Adatia, G.J. Kemp, D.J. Taylor, G.K. Radda, B. Rajagopalan and S.G. Haworth, Clin. Sci. 85 (1993), $105-109$.

[107] C.H. Thompson, Y.S. Green, J.G. Ledingham, G.K. Radda and B. Rajagopalan, Acta Physiol. Scand. 147 (1993), 85-90.

[108] F. Duhaylongsod, J. Greibel, D. Bacon, W. Wolfe and C. Piantadosi, J. Appl. Physiol. 75 (1993), 790-797.

[109] G. Walter, K. Vandenborne, M. Elliot and J. Leigh, J. Physiol. 519 (1999), 901-970.

[110] K. Roth and M.W. Weiner, Magn. Reson. Med. 22 (1991), 505-511.

[111] G.J. Kemp, L.J. Hands, G. Ramaswami, D.J. Taylor, A. Nicolaides and G.K. Radda, Clin. Sci. 89 (1995), 581-590.

[112] L. Edström, E. Hultman and K. Sahlin, J. Physiol. 332 (1982), 47-58.

[113] J. Bangsbo, L. Johansen, B. Quistorff and B. Saltin, J. Appl. Physiol. 74 (1993), 2034-2039.

[114] P.N. Ventakasubramanian, M.F. Mafee and M. Barany, Magn. Reson. Med. 6 (1988), 359-363.

[115] R. Buchli, D. Meier, E. Martin and P. Boesiger, Magn. Reson. Med. 32 (1994), 453-458.

[116] J.F. Dunn, G.J. Kemp and G.K. Radda, NMR Biomed. 5 (1992), 154-160.

[117] R. Buchli and P. Boesiger, Magn. Reson. Med. 30 (1993), 552-558.

[118] R. Rico-Sanz, J. Appl. Physiol. 88 (2000), 1181-1191.

[119] A. Ratkevicius, M. Mizuno, E. Povilonis and B. Quistorff, J. Physiol. 507(Pt 2) (1998), 593-602.

[120] H. Wackerhage, U. Hoffmann, D. Essfeld, D. Leyk, K. Mueller and J. Zange, J. Appl. Physiol. 85 (1998), $2140-2145$.

[121] G.J. Kemp, D.J. Taylor, J.F. Dunn, S.P. Frostick and G.K. Radda, J. Neurol. Sci. 116 (1993), 201-206.

[122] M.J. Kushmerick, Am. J. Physiol. 272 (1997), C1739-C1747.

[123] R.M. Marrades, J. Roca, J.M. Campistol, O. Diaz, J.A. Barbera, J.V. Torregrosa, J.R. Masclans, A. Cobos, R. Rodriguez Roisin and P.D. Wagner, J. Clin. Invest. 97 (1996), 2092-2100.

[124] J. Bangsbo, L. Johansen, T. Graham and B. Saltin, J. Physiol. 462 (1993), 115-133.

[125] R.S. Richardson, E.A. Noyszewski, K.F. Kendrick, J.S. Leigh and P.D. Wagner, J. Clin. Invest. 96 (1995), $1916-1926$.

[126] M.C. van Beekvelt, B.G. van Engelen, R.A. Wevers and W.N. Colier, Ann. Neurol. 46 (1999), 667-670.

[127] B. Chance and W. Bank, Biochim. Biophys. Acta 1271 (1995), 7-14. 


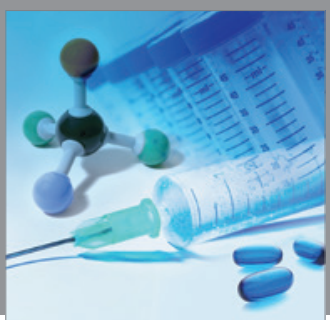

International Journal of

Medicinal Chemistry

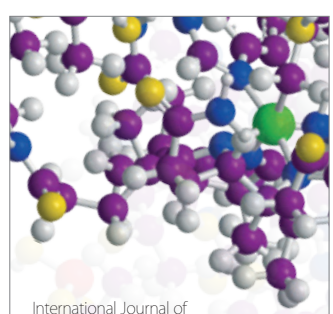

Carbohydrate Chemistry

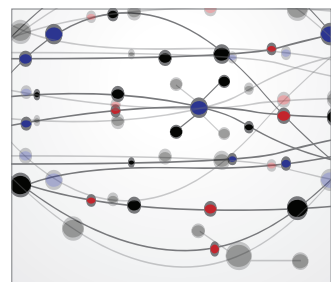

The Scientific World Journal
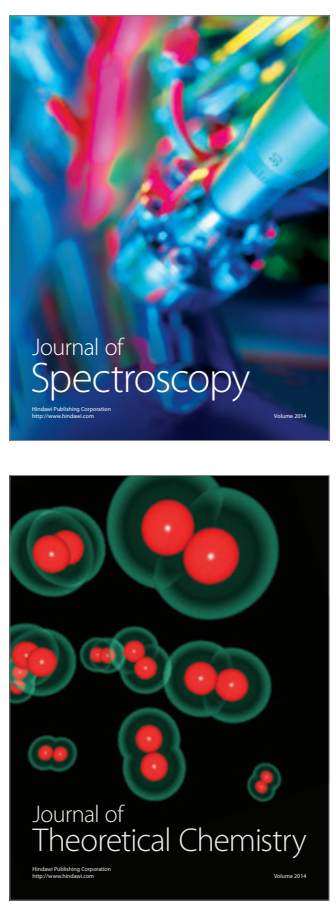
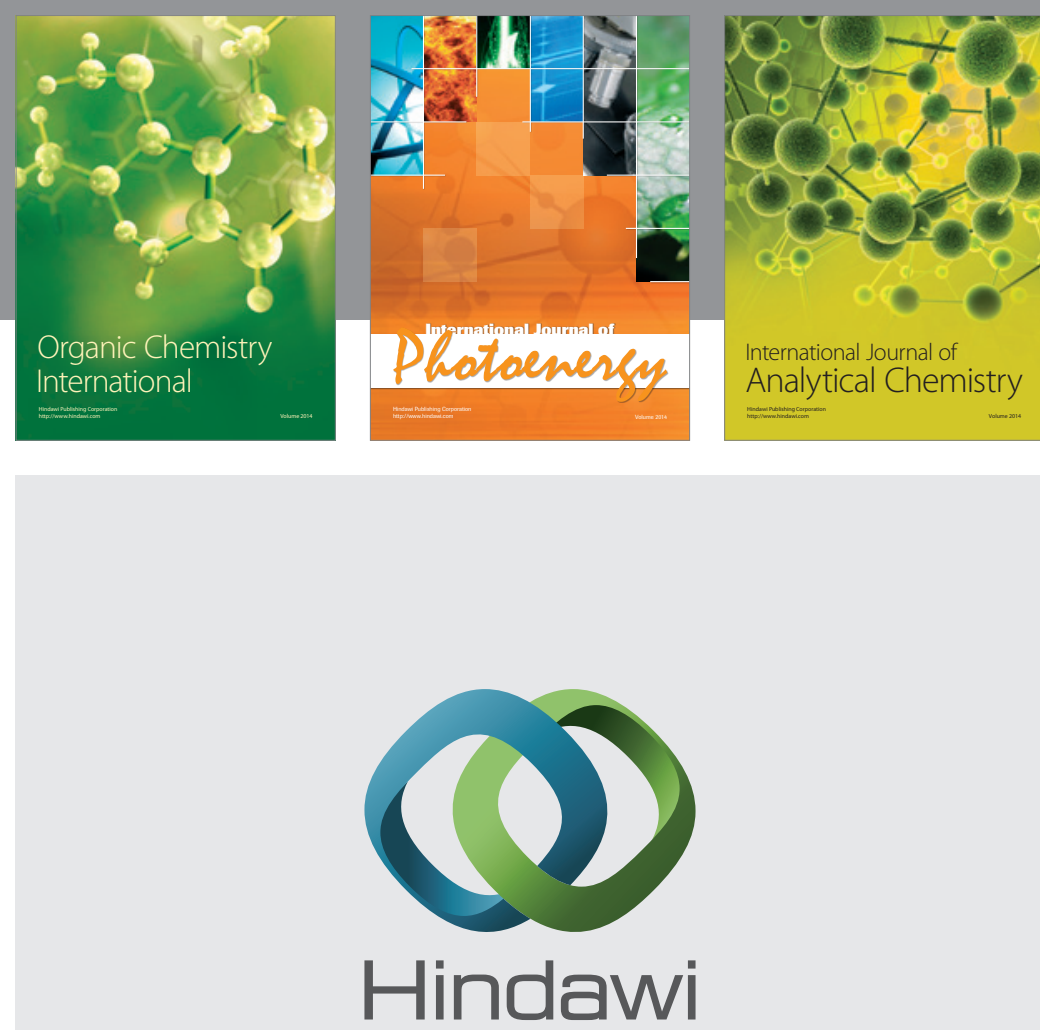

Submit your manuscripts at

http://www.hindawi.com
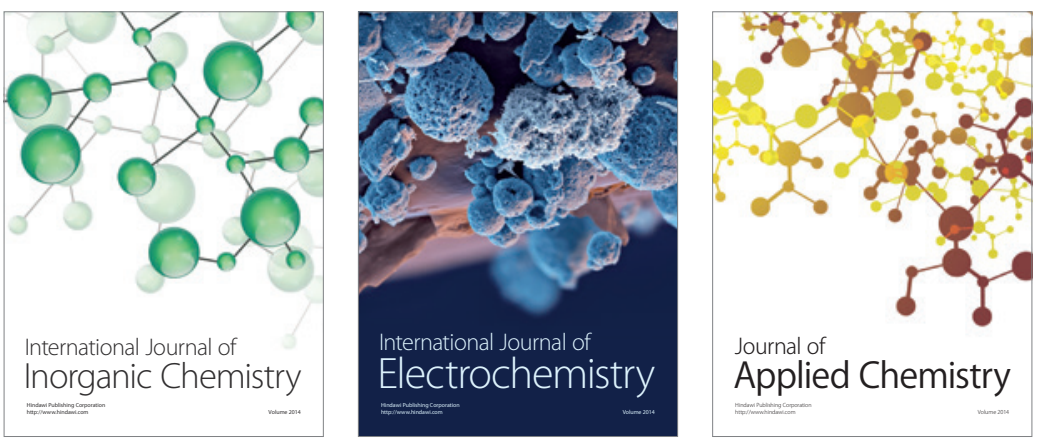

Journal of

Applied Chemistry
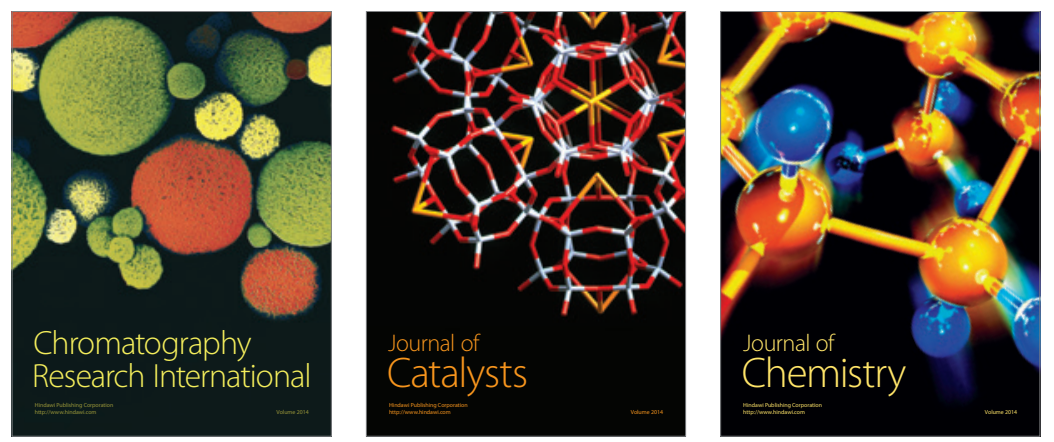
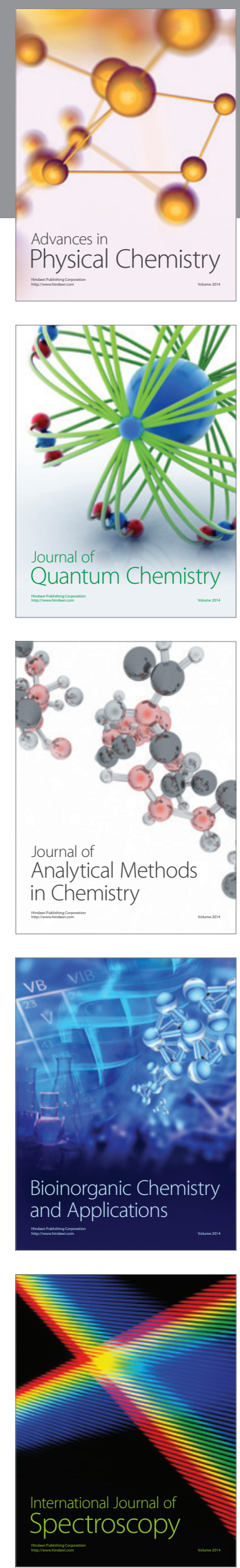